e-Journal of Educational

Research, Assessment and Evaluation

\section{REIIEVE}

Revista ELectrónica de Investigación y EValuación Educativa

\title{
DISEÑO Y PROPIEDADES PSICOMÉTRICAS DEL AVACO- EVADIE. CUESTIONARIO PARA LA EVALUACIÓN DE LA ATENCIÓN A LA DIVERSIDAD COMO DIMENSIÓN EDUCATIVA EN LAS INSTITUCIONES ESCOLARES
}

\section{[Design and psychometric properties of AVACO-EVADIE. Questionnaire for the evaluation of the diversity attention as an educational dimension in the school institutions]}

\section{Article record \\ $\underline{\text { About authors }}$ \\ HTML format}

\author{
por \\ Biencinto-López, Chantal (alameda@edu.ucm.es) \\ González-Barbera, Coral (cgbarbera@edu.ucm.es) \\ García-García, Mercedes (mergarci@edu.ucm.es) \\ Sánchez-Delgado, Purificación (Purificacion.Sanchez@uv.es) \\ Madrid-Vivar, Dolores (lmadrid@uma.es)
}

$\underline{\text { Ficha del artículo }}$

$\underline{\text { Sobre los autores }}$

Formato HTML

\begin{abstract}
This article shows the process taken to design and identify the psychometric properties of the evaluation instrument construct Diversity Attention as a context variable. For that, the starting point is a brief revision of different instruments used to collect information on diversity, not only cultural but also social, linguistic or on capacities. After that, and assuming a classification of the different theoretical approaches, a first instrument is made, committing ourselves to an inclusive approach. After that, its validation is made by experts and its pilot study is carried on. Reliability analysis of the instrument helps us to conclude that the questionnaire is reliable on collecting information regarding how schools face diversity attention.
\end{abstract}

\section{Keywords}

Diversity attention, context variables, inclusive approach, evaluation of educational systems.

\section{Resumen}

El presente artículo muestra el proceso seguido para diseñar e identificar las propiedades psicométricas del instrumento de evaluación del constructo Atención a la Diversidad como variable de contexto. Para ello, se ha comenzado con una pequeña revisión de los instrumentos utilizados para recoger información sobre la diversidad tanto cultural como social, lingüística o en capacidades. A continuación y, partiendo de una clasificación de los distintos enfoques teóricos, se ha construido un primer instrumento, apostando por un enfoque inclusivo. Posteriormente se procede a una validación por expertos. Tras la validación se toma la decisión de subdividir el instrumento original en cuatro instrumentos, uno por audiencia encuestada y por último al pilotaje del mismo. El análisis de la fiabilidad del instrumento nos lleva a la conclusión de que se trata de un cuestionario fiable para recoger información acerca de como afrontan los centros la Atención a la Diversidad.

\section{Descriptores}

Atención a la diversidad, variables de contexto, perspectiva inclusiva, evaluación de sistemas educativos. 


\section{Introducción}

El objetivo principal de este artículo es el diseño y posterior identificación de las propiedades psicométricas de un instrumento de evaluación del constructo Atención a la Diversidad en los centros, desde una perspectiva del contexto de los mismos.

Cabe destacar que para comprender en profundidad el citado objetivo sería necesario complementar la lectura de este artículo con la de otro (García García et al., 2009) donde se expone un enfoque teórico del constructo que se pretende medir con el instrumento elaborado.

El diseño de este instrumento se enmarca dentro de un Proyecto de Investigación y Desarrollo (Jornet Meliá, 2004) titulado: "Análisis de Variables de Contexto: diseño de instrumentos para la evaluación de sistemas educativos". En este proyecto se pretende llevar a cabo un proceso de investigación evaluativo dirigido al diseño y desarrollo de Cuestionarios de Contexto para la evaluación de sistemas educativos. Para ello, el punto de partida es revisar las variables de entrada, proceso y contexto, usuales en los planes de evaluación de sistemas educativos, desde una perspectiva métrico-diferencial. El objetivo es analizar el valor diferencial de las mismas en relación con el rendimiento educativo -como variable central de resultado o producto-, los instrumentos disponibles para su medición y/o evaluación y las posibilidades de integrar este tipo de soluciones métricas en cuestionarios o escalas utilizables en evaluaciones de sistema educativo en la Educación Primaria y en la Educación Secundaria Obligatoria. En definitiva, se trata de diseñar instrumentos de contexto que coadyuven a mejorar la utilidad de las evaluaciones de sistemas educativos, en función de su calidad para explicar el rendimiento y orientar las decisiones de intervención sobre el sistema.

Los objetivos del citado proyecto, se pueden sintetizar en los siguientes: 1) Análisis de variables de entrada, proceso y contexto para la evaluación de sistemas educativos; 2) Diseño de Cuestionarios de Contexto; y, 3) Validación de instrumentos. El presente artículo contiene aspectos que dan respuesta al segundo y tercer objetivo.
Partiremos de una breve conceptualización teórica del constructo que da paso a la elaboración de la tabla de especificaciones. Finalmente presentaremos los primeros resultados tras la validación de expertos y el pilotaje del instrumento.

\section{Conceptualización}

Partimos del concepto de Atención a la Diversidad como cualquier acción educativa diseñada sistemáticamente para aquellos estudiantes que presentan diferencias (individuales o grupales) asociadas a los resultados educativos, con objeto de asegurar la equidad educativa (García García et al., 2007). A partir de esta definición, hemos centrado la revisión teórica del concepto en la clasificación de los distintos enfoques que coexisten en los centros sobre como atender las diferencias tanto a nivel individual como de grupo.

En este sentido, las diferencias encontradas entre los diversos enfoques suponen una forma diferente de enfrentarse a la diversidad (seleccionándola o integrándola), de priorizar las metas educativas a lograr (de equidad o de desarrollo de la individualidad), de plantear los tratamientos educativos (específicos, compensatorios, variados), que se sitúan a lo largo de la dimensión Atención a la Diversidad. En un polo estarían aquellos centros que identifican las diferencias de los estudiantes para separarles, diseñando planes ajustados dirigidos a grupos identificados de estudiantes. En el otro polo, los que identifican las diferencias para atenderlas educativamente; es decir, los que diseñan planes ajustados a las diferencias individuales de todos y cada uno de los estudiantes que están en el aula para ayudarles a conseguir los objetivos a la vez que desarrollan sus aptitudes.

Por consiguiente, entendemos que atender la diversidad de los estudiantes toma diferentes formas que se dirigen de la exclusión de las diferencias para tratarlas fuera de los grupos ordinarios a la inclusión de las diferencias para tratarlas individualmente en el aula.

En la tabla 1, podemos comprobar las diferentes apreciaciones según el enfoque teórico utilizado para abordar las diferencias de los estudiantes. 


\begin{tabular}{|c|c|c|c|}
\hline DIVERSIDAD & $\begin{array}{c}\text { Fuera de la norma } \\
\text { Grupos extremos } \\
\text { Dificultad de adaptación } \\
\text { Deficiencia }\end{array}$ & $\begin{array}{l}\text { Diferencias grupales asociadas a necesi- } \\
\text { dades educativas específicas }\end{array}$ & $\begin{array}{l}\text { Diferencias individuales } \\
\text { predictoras de aprendizaje/rendimiento } \\
\text { Se reconoce como legítima ("normal") } \\
\text { Inclusivo (incluye a todos, no sólo a NEE) }\end{array}$ \\
\hline
\end{tabular}

TABLA 1. Enfoques teóricos

\section{Diseño y construcción del cuestiona- rio EVADIE}

Teniendo en cuenta la clasificación de los enfoques teóricos, hemos elaborado la tabla de especificaciones donde se recogen las ocho dimensiones que componen el cuestionario. Se han elegido estas dimensiones porque cada enfoque las concibe y plantea de forma diferente para atender la diversidad.
En la tabla 2, aparecen tanto las dimensiones especificadas como los indicadores de cada una de ellas, esto nos servirá de referencia para la construcción de los ítems que compondrán el cuestionario. 


\begin{tabular}{|c|c|c|c|}
\hline & ENFOQUE DE EXCLUSIÓN & ENFOQUE INTEGRADOR & ENFOQUE INCLUSIVO \\
\hline EN LA ESCUELA & $\begin{array}{l}\text { - Identificar los centros que no } \\
\text { tienen co-educación } \\
\text { - Identificar en los centros si exis- } \\
\text { ten grupos diferentes en función de } \\
\text { la capacidad de adaptación de los } \\
\text { sujetos } \\
\text { - Clasificar los diferentes grupos } \\
\text { - Conocer el nivel de adaptación } \\
\text { de los sujetos al sistema vigente }\end{array}$ & $\begin{array}{l}\text { - Identificar y clasificar las atenciones educativas diferen- } \\
\text { ciadas } \\
\text { - Considerar la promoción de los alumnos de manera dife- } \\
\text { rente en función de sus capacidades } \\
\text { - Dirigir a los sujetos a opciones profesionales diferentes } \\
\text { según su capacidad } \\
\text { - Considerar que el sistema debe adaptarse al estudiante } \\
\text { con el fin de compensar sus carencias de capacidad }\end{array}$ & $\begin{array}{l}\text { - Considerar a todos los alumnos diferentes y con múltiples } \\
\text { capacidades } \\
\text { - Proporcionar ocasiones para que todos logren los objeti- } \\
\text { vos. } \\
\text { - Trabajar, en ocasiones, con grupos flexibles según el tipo } \\
\text { de actividad o capacidad o nivel de aprendizaje } \\
\text { - Construir un proyecto común y una organización inclusi- } \\
\text { va (reorganización interna, participación de los miembros y } \\
\text { estructuradas redes de apoyo) } \\
\text { - Adaptar los métodos y estrategias educativas a los estu- } \\
\text { diantes } \\
\text {-Lograr un estilo dinámico de la dirección flexible a las } \\
\text { diferentes situaciones } \\
\text { - Establecer tiempos comunes para la coordinación del } \\
\text { profesorado } \\
\text { - Distribuir los espacios y recursos según las necesidades } \\
\text { del centro }\end{array}$ \\
\hline $\begin{array}{l}\text { VALORACIÓN } \\
\text { DEL NIVEL DE } \\
\text { RENDIMIENTO }\end{array}$ & $\begin{array}{l}\text { - Concebir los niveles de rendi- } \\
\text { miento como algo externo y no- } \\
\text { modificable } \\
\text { - Considerar diferencias entre títu- } \\
\text { los }\end{array}$ & $\begin{array}{l}\text { - Considerar diferentes niveles de logro para cada grupo } \\
\text { diferenciado } \\
\text { - Plantear objetivos comunes }\end{array}$ & $\begin{array}{l}\text { - Considerar el rendimiento o progreso de cada alumno en } \\
\text { función de sus propias capacidades } \\
\text { - Plantear objetivos mínimos y comunes y objetivos indivi- } \\
\text { duales para cada alumno }\end{array}$ \\
\hline $\begin{array}{l}\text { CONCEPTO DE } \\
\text { NORMALIDAD }\end{array}$ & $\begin{array}{l}\text { - Entender que el concepto de } \\
\text { normalidad coincide con el del } \\
\text { grupo normativo }\end{array}$ & $\begin{array}{l}\text { - Concebir la normalidad como un reflejo de la sociedad } \\
\text { heterogénea } \\
\text { - Considerar alumnos normales a todos aquello no etique- } \\
\text { tados psicopedagógicamente }\end{array}$ & $\begin{array}{l}\text { - Concebir la diferencia como lo normal. } \\
\text { - Considerar a todos los alumnos dentro de la norma, con } \\
\text { sus puntos fuertes y débiles }\end{array}$ \\
\hline $\begin{array}{l}\text { CONCEPTO DE } \\
\text { DIVERSIDAD }\end{array}$ & $\begin{array}{l}\text { - Entender el concepto diversidad } \\
\text { como algo negativo y fuera de la } \\
\text { norma } \\
\text { - Entender la diversidad como la } \\
\text { dificultad de adaptarse a la norma }\end{array}$ & $\begin{array}{l}\text { - Entender el concepto de diversidad como grupos exclui- } \\
\text { dos por diferencias asociadas a desventajas educativas } \\
\text { - Identificar las tipologías en función de las necesidades } \\
\text { educativas requeridas } \\
\text { - Concebir las necesidades como propias de los alumnos } \\
\text { - Basarse en la idea de recuperación más que de prevención }\end{array}$ & $\begin{array}{l}\text { - Entender el concepto de diversidad como algo positivo, } \\
\text { normal y enriquecedor } \\
\text { - Entender las diferencias como individuales (inter e in- } \\
\text { traindividuales) } \\
\text { - Concebir las necesidades como propias de la escuela, } \\
\text { trabajando en un proyecto común de mutuo apoyo }\end{array}$ \\
\hline
\end{tabular}




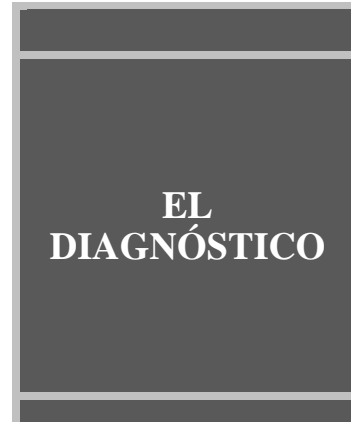

LA INTERVEN-

CIÓN MÁS

APROPIADA

EN EL CURRÍCULO

\section{ENFOQUE DE EXCLUSIÓN}

- Centrar el diagnóstico de los

alumnos en sus capacidades cognitivas básicas y en sus diferencias grupales

- Identificar a los estudiantes con el fin de excluirlos de la vía ordinaria

- Distinguir entre alumnos normales y alumnos especiales

- Separar a los estudiantes en grupos

- Plantear currículos diferentes, con elementos diferentes, para cada grupo

- Tratar a los alumnos diferentes con personal especializado

\section{ENFOQUE INTEGRADOR}

- Centrar el diagnóstico en las necesidades cognitivas y actitudinales

- Identificar a los alumnos con necesidades educativas

especiales con el fin de asignar el tratamiento más adecua-

do

- Etiquetar a los alumnos

- Integrar a los todos los alumnos en el mismo grupo o

clase con los apoyos específicos y las adaptaciones necesarias.

- Intentar recuperar a los alumnos con necesidades educa-

tivas especiales para adaptarlos al sistema

- Plantear un mismo currículo incluyendo las adaptaciones necesarias para obtener unos objetivos mínimos.

- Tratar a los alumnos en el aula con apoyo especializado

\section{TABLA 2. Tabla de especificaciones}

\section{ENFOQUE INCLUSIVO}

- Centrar el diagnóstico en diferentes y múltiples aspectos, relacionados con el éxito académico

- Identificar las aptitudes y estilos adecuados a los objetivos educativos para utilizar las estrategias adecuadas a ello

- Identificar las diferencias para ajustar el tratamiento educativo

- Agrupar a los alumnos de manera flexible en función del objetivo de la actividad o el nivel del estudiante, alternando grupos heterogéneos y homogéneos

-Plantear un núcleo central y común de objetivos

- Incluir en el currículo mucha optatividad para crear diferentes itinerarios

- Trabajar cooperativamente en equipos multidisciplinares encargados de adaptar los currículum a las necesidades puntuales de las situaciones 
En función de los indicadores de la tabla de especificaciones y, revisando los distintos instrumentos existentes (Jiménez Trens, 2004; Cifuentes, 2003; Booth y Ainscow, 2001) se ha construido un cuestionario con la siguiente estructura:

- 6 cuestiones sobre información personal.

- 9 cuestiones sobre información del centro.

- 3 cuestiones sobre procedencia del alumnado.

-1 cuestión sobre las características del alumnado con Necesidades Educativas Específicas (NEEs).

-2 cuestiones sobre las distintas dimensiones seleccionadas (recursos, centro, concepto de normalidad, concepto de diversidad, intervención del centro, diagnóstico de los alumnos, curriculum y nivel de rendimiento).

En conjunto se elaboraron 21 cuestiones que representan a todas las dimensiones, con las siguiente estructura (tabla 3): 44 ítems para la dimensión de recursos (tanto de existencia o no del recurso, así como el grado de utilización del mismo); 16 ítems dentro de la dimensión relativa al centro (se pide tanto la opinión personal con cada una de las afirmaciones, como desde la perspectiva del centro donde trabaja el encuestado/a); 5 ítems sobre el concepto de normalidad (tanto desde una perspectiva individual como de centro de pertenencia); 10 ítems sobre el concepto de diversidad (como en las dimensiones anteriores, desde un punto de vista personal e institucional); 4 ítems de intervención; 9 sobre el diagnóstico de los alumnos; 6 ítems sobre currículo; y, 6 ítems sobre el nivel de rendimiento de los alumnos (todas las dimensiones están valoradas desde las dos perspectivas mencionadas anteriormente con la idea de valorar la coherencia en la percepción sobre la diversidad que valora respecto de sí mismo/a y la que percibe en el centro donde trabaja).

\begin{tabular}{|c|c|c|c|c|c|c|c|c|}
\cline { 2 - 9 } \multicolumn{1}{c|}{} & \multicolumn{9}{c|}{ DIMENSIONES } \\
\cline { 2 - 9 } \multicolumn{1}{c|}{} & RECURSOS & CENTRO & $\begin{array}{c}\text { CONCEPTO } \\
\text { NORMALIDAD }\end{array}$ & $\begin{array}{c}\text { CONCEPTO } \\
\text { DIVERSIDAD }\end{array}$ & INTERVENCIÓN & DIAGNÓSTICO & CURRICULUM & $\begin{array}{c}\text { NIVEL DE } \\
\text { RENDIMIENTO }\end{array}$ \\
\hline $\mathbf{N}^{\mathbf{0}}$ & 44 & 16 & 5 & 10 & 4 & 9 & 6 & 6 \\
ÍTEMS & 4 & 5 & & 4 & 6 & 6 \\
\hline
\end{tabular}

Tabla 3. Estructura del cuestionario

El cuestionario original se presenta en el Anexo I.

\section{Propiedades psicométricas del ins- trumento}

\subsection{Validación por expertos}

Para la validación del instrumento EVADIE, contamos con la participación de 17 expertos: cinco expertos en la Comunidad de Madrid (dos profesores de universidad y tres orientadores de centros de secundaria); siete expertos de la Comunidad Valenciana (un profesor de universidad, cuatro pedagogos, una psicopedagoga y un psicólogo); y cinco expertos de Andalucía (dos profesores de universidad, dos maestros de educación especial y un especialista). Se ha utilizado una pauta en la que se pide a los expertos su valoración acerca de la pertinencia del ítem y la relevancia de la información que aporta. Por otro lado, se les pidió su opinión acerca de la adecuación de las distintas fuentes de recogida de información (audiencias) y por último la pertinencia del ítem en las etapas educativas: Educación primaria y Educación Secundaria.
Tras la recepción y análisis de la pauta de validación se tomó la decisión, de acuerdo con las sugerencias de los expertos, de dividir el instrumento completo por audiencias para acortarlo, de tal forma que finalmente se elaboraron cuatro instrumentos, uno por audiencia (director, inspector, orientador/especialista y profesor). Como criterio de selección de los distintos ítems, se utilizó un índice de consenso en las respuestas del $75 \%$. En la tabla 4 , se presentan los principales resultados de la validación por expertos en cuanto a ítems y a dimensiones de pertenencia. Para disminuir la longitud del cuestionario también se decide eliminar parte de los Recursos, aquellos que todos los centros con diversidad tienen a coste de la administración o que son infrecuentes (Programas de Diversificación Curricular; Aulas de castellanización; Servicio de Apoyo Educativo Domiciliario; Hospital de DíaCentro educativo terapéutico, etc.) y, por el contrario, se mantienen aquellos que suponen una acción diferente o una búsqueda de recursos específicos (Apoyo del profesor en el aula; Desdobles; Monitores de Apoyo; Alumnos ayudantes; etc.). 


\begin{tabular}{|c||c|c|c|}
\hline DIMENSIÓN & $\begin{array}{c}\text { ÍTEMS } \\
\text { DISEÑADOS }\end{array}$ & $\begin{array}{c}\text { ÍTEMS } \\
\text { ELIMINADOS }\end{array}$ & $\begin{array}{c}\text { ÍTEMS } \\
\text { AÑADIDOS }\end{array}$ \\
\hline Recursos & 44 & 18 & 4 \\
\hline Centro & 16 & 3 & 0 \\
\hline \hline Normalidad & 5 & 5 & 0 \\
\hline \hline Diversidad & 10 & 6 & 0 \\
\hline \hline Intervención & 4 & 0 & 0 \\
\hline Diagnóstico & 9 & 2 & 0 \\
\hline Currículo & 6 & 1 & 0 \\
\hline Rendimiento & 6 & 1 & 0 \\
\hline
\end{tabular}

TABLA 4. Validación de ítems por dimensiones
Como se argumenta al comienzo de este epígrafe y, con los resultados de la validación de expertos como referente, se tomó la decisión de elaborar cuatro instrumentos diferenciados por audiencia. El criterio principal utilizado ha sido el conocimiento/experiencia de los encuestados, así como el conocimiento práctico sobre los distintos aspectos evaluados (ver anexo II).

En la tabla 5, se presentan las dimensiones comunes y diferenciadas para cada una de las audiencias.

\begin{tabular}{|c|c|c|c|c|c|c|c|}
\cline { 2 - 8 } \multicolumn{1}{c|}{} & RECURSOS & CENTRO & DIVERSIDAD & INTERVENCIÓN & DIAGNÓSTICO & CURRICULUM & RENDIMIENTO \\
\hline INSPECTOR & & $\mathrm{X}$ & $\mathrm{X}$ & & & & \\
\hline DIRECTOR & & $\mathrm{X}$ & $\mathrm{X}$ & $\mathrm{X}$ & & $\mathrm{X}$ & \\
\hline ESPECIALISTA & $\mathrm{X}$ & & $\mathrm{X}$ & $\mathrm{X}$ & $\mathrm{X}$ & $\mathrm{X}$ & \\
\hline DOCENTE & $\mathrm{X}$ & $\mathrm{X}$ & $\mathrm{X}$ & & & $\mathrm{X}$ & \\
\hline
\end{tabular}

Tabla 5. Dimensiones diferenciadas por audiencia

\subsection{Pilotaje del instrumento}

Como complemento a la validación por expertos, se procedió al pilotaje de los distintos instrumentos. El cuestionario se pilotó en las tres comunidades autónomas que participan en el Proyecto I $+D$, citado al comienzo. Tras realizar un muestreo incidental ${ }^{1}$ que considerando el conjunto de las audiencias ascendía a 18 centros de la Comunidad de Madrid; 18 centros en Andalucía; y, 17 centros de la Comunidad Valenciana, se recibieron finalmente 300 respuestas: 54 de directores de centros (tanto de primaria como de secundaria), 85 de orientadores/especialistas, 136 de docentes y 25 de inspectores.

Los análisis de datos se han realizado con ayuda del paquete estadístico SPSS vs. 15, consistiendo fundamentalmente en estudiar la consistencia interna (con el estadístico Alpha de Cronbach) de los cuatro instrumentos, considerando tanto el conjunto de sus ítems (total de la prueba) como agrupados en las dimensiones teóricas de partida. Además se ha realizado un análisis de los valores perdidos tomando la decisión de reemplazar dichos valores por la mediana, ya que se trata de variables medidas con una escala tipo Lickert con 6 categorías.

Finalmente cabe destacar que, en el contexto del Proyecto citado y aunque no es objetivo de este trabajo, estos instrumentos han sido reducidos en longitud con el fin de seleccio- nar algunos de sus ítems para formar parte de un instrumento general de contexto que permita tomar medidas fiables para predecir el rendimiento. De esta reducción destacamos el hecho de que las puntuaciones desde la perspectiva personal y de centro en cada uno de los ítems correlacionan alta y significativamente, por ello en el siguiente epígrafe analizaremos únicamente la perspectiva de centro que, a su vez, es un elemento común a todos los ítems y dimensiones.

\section{Resultados}

Del análisis de los cuestionarios recibidos podemos extraer fundamentalmente los siguientes resultados acerca del grado de consistencia interna de los mismos. Para ello hemos calculado el estadístico alpha de Cronbach (1951), teniendo como referencia para su interpretación el baremo que establece Nunnelly $(1978)^{*}$. Cabe destacar que las dimensiones incluidas en los distintos instrumentos tiene la misma longitud, es decir el mismo número de ítems.

\subsection{Cuestionario para profesores}

\subsubsection{Análisis de la fiabilidad}

La fiabilidad del conjunto de los ítems, como podemos apreciar en la tabla 6 , es 0,920 . En función del baremo propuesto, se trata de un valor muy bueno para el estadístico de Cronbach, y por tanto podemos hablar de un instrumento excelente. 


\begin{tabular}{|c|c|}
\hline Alfa de Cronbach & N de elementos \\
\hline 0,920 & 90 \\
\hline
\end{tabular}

TABLA 6. Fiabilidad del cuestionario completo para profesores
Centrando el análisis de la fiabilidad en cada una de las dimensiones que componen el cuestionario, se presenta la tabla resumen que sigue (tabla 7).

\begin{tabular}{|c|c|c|c|c|c|}
\hline DIMENSIONES & RECURSOS & CENTRO & $\begin{array}{c}\text { CONCEPTO } \\
\text { DE DIVER- } \\
\text { SIDAD }\end{array}$ & CURRICULUM & $\begin{array}{c}\text { NIVEL DE } \\
\text { RENDIMIENTO }\end{array}$ \\
\hline $\begin{array}{c}\text { Alpha de Cron- } \\
\text { bach }\end{array}$ & 0,849 & 0,876 & 0,890 & 0,762 & 0,632 \\
\hline
\end{tabular}

TABLA 7. Fiabilidad por dimensiones del cuestionario para profesores

En todas las dimensiones encontramos fiabilidades buenas a excepción de las dimensiones Currículum, cuya fiabilidad es aceptable, y Nivel de Rendimiento que presenta una fiabilidad calificada de débil.

\subsubsection{Análisis de la estructura interna}

Dada la falta de muestra para tres de las audiencias encuestadas, hemos considerado analizar la estructura interna del instrumento para docentes del que contamos con 136 respuestas. La técnica estadística utilizada para el análisis de la estructura que subyace al ins- trumento ha sido el Análisis Factorial Clásico, utilizando el procedimiento de componentes principales. Analizando la significatividad o no de las relaciones entre variables, comprobamos (tabla 8), como ambos resultados nos indican la adecuación del análisis factorial a los datos. Por un lado, y teniendo en cuenta el criterio mayor de 0,60 , podemos considerar el valor KMO significativo. De la misma forma consideramos significativa la matriz de correlaciones mediante la prueba de esfericidad de Barlett $(\mathrm{p} \leq 0.05)$.

\begin{tabular}{|ll|r|}
\hline Medida de adecuación muestral de Kaiser-Meyer-Olkin &, 753 \\
Prueba de esfericidad de Bartlett & Chi-cuadrado aproximado & 3238,502 \\
& gl & 946 \\
Sig. &, 000 \\
\hline
\end{tabular}

Tabla 8. Test de esfericidad de Barlett

\begin{tabular}{|l|r|r|r|}
\hline Componente & \multicolumn{3}{|c|}{ Suma de las saturaciones al cuadrado de la rotación } \\
\cline { 2 - 4 } & Total & \% de la varianza & \% acumulado \\
\hline $\mathbf{1}$ & 5,704 & 12,965 & 12,965 \\
$\mathbf{2}$ & 5,329 & 12,112 & 25,077 \\
$\mathbf{3}$ & 5,251 & 11,934 & 37,011 \\
$\mathbf{4}$ & 2,715 & 6,170 & 43,181 \\
$\mathbf{5}$ & 1,870 & 4,251 & 47,431 \\
\hline
\end{tabular}

Tabla 9. Porcentaje de varianza explicada

Con la extracción de 5 factores logramos explicar el $47,43 \%$ de varianza (tabla 9), se trata de un porcentaje que no es suficiente aunque como podemos comprobar en el gráfico 1, es a partir del quinto factor donde el ritmo al que se acumula la varianza explicada empieza a decrecer (Kaiser, 1960). 


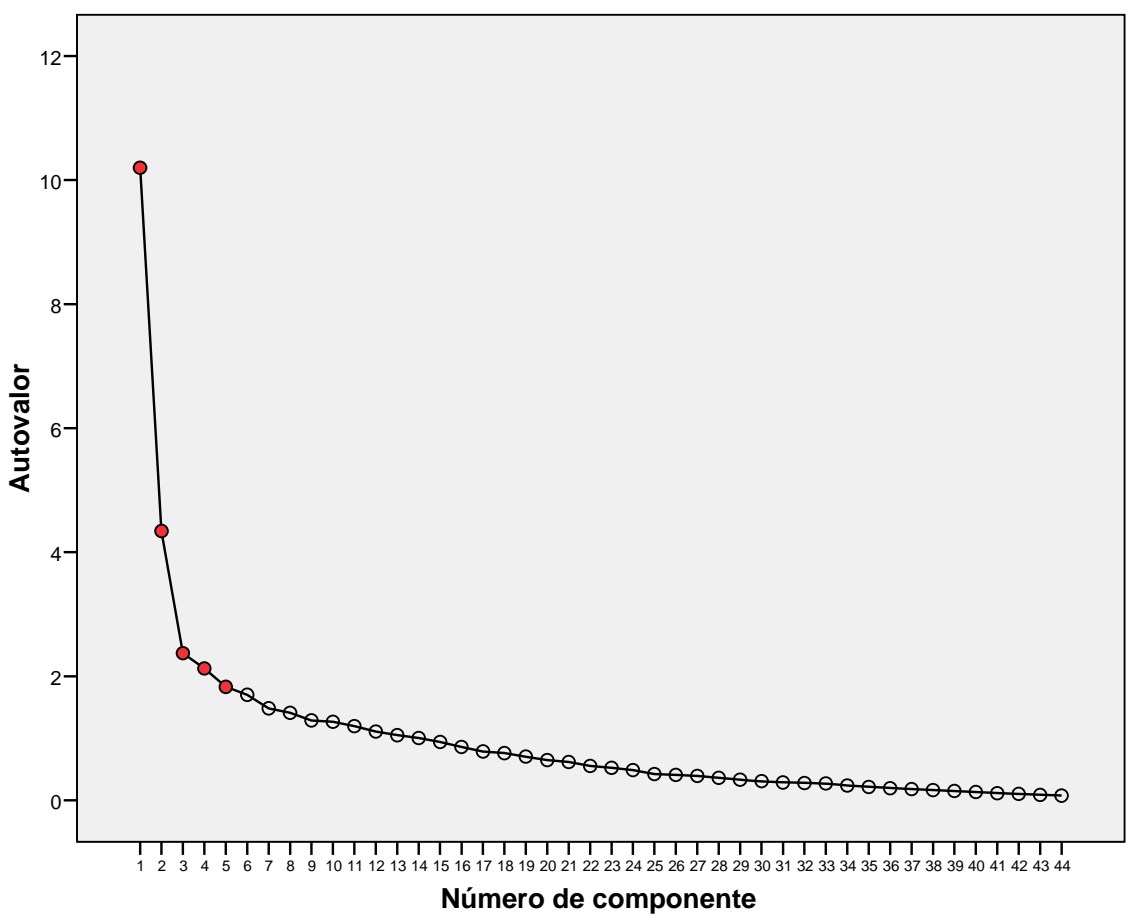

Gráfico 1. Gráfico de sedimentación

Del análisis de los resultados podemos destacar, en primer lugar, que las comunalidades nos indican que la mayoría de las variables no están bien representadas en la solución factorial $(<0,60)$. Asumiendo la falta de representatividad, esbozamos una posible interpretación sustantiva de la matriz de componentes rotados vinculada no solo con la estructura propia del cuestionario sino también con los diferentes enfoques teóricos de los que partimos (Véase tabla 2: matriz de especificaciones, combinación de enfoques y dimensiones en el cuestionario). De esta forma, los factores extraídos corresponderían, en función de las variables con cargas significativas, con la siguiente estructura:

\begin{tabular}{|l|l|l|l|l|l|}
\cline { 2 - 6 } & \multicolumn{5}{|c|}{ FACTORES } \\
\cline { 2 - 6 } & $\begin{array}{l}\text { FACTOR I. Centro / } \\
\text { Curriculum Inclusivo }\end{array}$ & $\begin{array}{l}\text { FACTOR II. } \\
\text { Recursos inclu- } \\
\text { sivos / Diversi- } \\
\text { dad Cultural }\end{array}$ & $\begin{array}{l}\text { FACTOR III. Recur- } \\
\text { sos inclusivos. Indivi- } \\
\text { dualización educativa }\end{array}$ & $\begin{array}{l}\text { FACTOR IV. } \\
\text { Resultados } \\
\text { inclusivos }\end{array}$ & $\begin{array}{l}\text { FACTOR } \\
\text { V. Exclusión }\end{array}$ \\
\hline \multirow{3}{*}{ VARIABLES } & $\begin{array}{l}\text { Ítems: } 2,4,6, \\
\text { Ítems: } 24,26,29, \\
30,37,39 \text { y } 40\end{array}$ & $\begin{array}{l}7,8,9,11,13, \\
18 \text { y } 21\end{array}$ & $\begin{array}{l}\text { Ítems: } 3,10,12,15,16,19,20 \text { y 22 } \\
16,17,19,2\end{array}$ & $\begin{array}{l}\text { Ítems: } 41,42 \\
\text { y } 44\end{array}$ & $\begin{array}{l}\text { Ítems: } 38 \text { y } \\
43\end{array}$ \\
\hline
\end{tabular}

* Véase anexo II (Cuestionario para Docentes)

Tabla 10. Definición de factores

En el Anexo III, hemos reproducido la matriz de componentes rotados.

\subsection{Cuestionario para orientado- res/especialistas}

La consistencia interna del cuestionario elaborado para orientadores y/o personal de apoyo a la diversidad, es de 0,919 (tabla 11). Pode- mos considerar el instrumento como excelente.

\begin{tabular}{|c|c|}
\hline Alfa de Cronbach & N de elementos \\
\hline 0,919 & 102 \\
\hline
\end{tabular}

TABLA 11. Fiabilidad del cuestionario completo para orientadores 
En la tabla 12 se presenta la fiabilidad de cada una de las dimensiones del cuestionario. Como se puede comprobar, algunas de las dimensiones son comunes para los cuatro cues- tionarios construidos al efecto, si embargo los valores de los coeficientes de fiabilidad cambian ligeramente puesto que la muestra de referencia es distinta.

\begin{tabular}{|c|c|c|c|c|c|c|}
\hline DIMENSIONES & RECURSOS & CENTRO & $\begin{array}{c}\text { CONCEPTO DE } \\
\text { DIVERSIDAD }\end{array}$ & INTERVENCIÓN & DIAGNÓSTICO & CURRICULUM \\
\hline $\begin{array}{c}\text { Alpha de } \\
\text { Cronbach }\end{array}$ & 0,874 & 0,867 & 0,856 & 0,691 & 0,800 & 0,705 \\
\hline
\end{tabular}

TABLA 12. Fiabilidad por dimensiones del cuestionario para orientadores

Se puede asumir que todas las dimensiones de esta escala presentan una consistencia interna entre buena y aceptable.

\subsection{Cuestionario para directores}

La fiabilidad del conjunto de los ítems de este cuestionario, así como la fiabilidad por di- mensiones, se presenta en las tablas 13 y 14 respectivamente.

\begin{tabular}{|c|c|}
\hline $\begin{array}{c}\text { Alfa de } \\
\text { Cronbach }\end{array}$ & $\begin{array}{c}\text { N de ele- } \\
\text { mentos }\end{array}$ \\
\hline 0,885 & 53 \\
\hline
\end{tabular}

TABLA 13. Fiabilidad del cuestionario completo para directores

\begin{tabular}{|c|c|c|c|c|}
\hline DIMENSIONES & CENTRO & $\begin{array}{c}\text { CONCEPTO DE } \\
\text { DIVERSIDAD }\end{array}$ & INTERVENCIÓN & CURRICULUM \\
\hline Alpha de Cronbach & 0,872 & 0,818 & 0,706 & 0,560 \\
\hline
\end{tabular}

TABLA 14. Fiabilidad por dimensiones del cuestionario para directores

Tanto la fiabilidad total como por dimensiones, se encuentra entre valores buenos y aceptables, a excepción de la escala Currículum que en este caso presenta una consistencia interna baja.

\subsection{Cuestionario para inspectores}

Para la última escala analizada se presenta, en la misma secuencia, tanto la fiabilidad total como la fiabilidad por dimensiones (tablas 15 y 16).

\begin{tabular}{|c|c|}
\hline Alfa de Cronbach & N de elementos \\
\hline 0,953 & 46 \\
\hline
\end{tabular}

TABLA 15. Fiabilidad del cuestionario completo para inspectores

\begin{tabular}{|c|c|c|c|}
\hline DIMENSIONES & CENTRO & $\begin{array}{c}\text { CONCEPTO DE } \\
\text { DIVERSIDAD }\end{array}$ & CURRICULUM \\
\hline Alpha de Cronbach & 0,930 & 0,802 & 0,794 \\
\hline
\end{tabular}

TABLA 16. Fiabilidad por dimensiones del cuestionario para inspectores

Comprobamos cómo la escala en su conjunto presenta una consistencia excelente, así como la dimensión de Centro, mientras que las restantes dimensiones presenta una consistencia buena pero algo menor.

En resumen, podemos afirmar que las escalas elaboradas presentan una consistencia interna entre buena y muy buena en su conjunto. Sin embargo algunas de las dimensiones, en concreto, Currículum en directores y Nivel de
Rendimiento en docentes, carecen aún de la consistencia interna suficiente para hacer claramente fiables sus resultados.

\section{Conclusiones}

De los resultados obtenidos en el procedimiento de diseño y análisis de las propiedades psicométricas de los distintos instrumentos, se extraen algunas conclusiones y propuestas. 
En primer lugar, presentamos unos instrumentos fiables que permiten medir los enfoques ante la atención a la diversidad que las distintas audiencias implicadas presentan, atendiendo a la teoría de partida. Si bien es cierto que debemos seguir trabajando en este aspecto, analizando cada ítem para eliminar o modificar los que corresponda procurando reducir la longitud de algunas de las escalas, es evidente que nuestra propuesta permite un primer acercamiento al modo en que se aborda la Atención a la Diversidad en los centros educativos.

Otra conclusión a destacar es el trabajo prospectivo que queda abierto respecto a la falta de comprobación, con los datos que se han manejado, de la estructura interna y por tanto de la validez de los instrumentos. Proponemos el aumento de muestra y el análisis pormenorizado de cada uno de los ítems y del conjunto de la prueba.

En tercer lugar, partiendo de la idea de que ninguno de los tres enfoques teóricos propuestos es mejor que otro sino diferente, se pretende en futuros trabajos analizar la coherencia que presentan en sus respuestas los diferentes implicados en el modo de abordar la Atención a la Diversidad en un mismo centro, puesto que la coherencia de la comunidad educativa en la forma de atender la diversidad en torno a un proyecto educativo, es el elemento que pudiera servir de indicador sobre la adecuación y eficacia de un determinado enfoque educativo.

Por último, resaltar que los últimos informes sobre la situación educativa de los estudiantes ponen de manifiesto un problema que sigue vigente en las aulas: el bajo rendimiento de los estudiantes en las materias instrumentales y un descontento por parte del profesorado, de los padres y de la sociedad en general. Nuestra propuesta es que dando una respuesta eficazmente ajustada a la diversidad se puede ayudar a paliar este problema ya que es uno de los pilares de la calidad educativa. La realidad pone en evidencia el incremento de la diversidad presente en las aulas y la dificultad de manejar esta situación. El reto, pues, es desarrollar un modelo educativo que paute y dé respuesta eficiente a las diferencias personales, ya provengan de distintas experiencias, estilos, capacidades o intereses, o de situaciones individuales y sociales diversas. Por ello, tener la posibilidad de diagnosticar y valorar, a través de unos cuestionarios fiables, el enfoque defendido por la Comunidad Educativa del centro puede ayudar a mejorar las propuestas de atención a la diversidad y, por qué no, la calidad del centro.

\section{BIBLIOGRAFÍA}

Ainscow, m. (2001). Desarrollo de escuelas inclusivas: Ideas, propuestas y experiencias para mejorar las instituciones. Madrid: Narcea.

Ainscow, M. (2001). Necesidades especiales en el aula: Guía para la formación del profesorado. Madrid: UNESCO.

Ainscow, M. et al. (2001). Hacia escuelas eficaces para todos: Manual para la formación de equipos docentes. Madrid: Narcea.

Booth, T.A. and Booth, W. (1998). Growing up with parents who have learning difficulties [Recurso electrónico]. London-New York: Routledge.

Casado Muñoz, R. y Cifuentes García, A. (2003). El acceso al empleo y a la universidad de las personas con discapacidad: barreras y alternativas. Actas de las III Jornadas sobre Universidad y Personas con Discapacidad, I Reunión Científica sobre la Respuesta Socio-educativa a la Discapacidad. Burgos: Universidad de Burgos.

Cronbach, L. J. (1951). Coefficient alpha and the internal structure of tests. Psychometrika, 16(3), 297-334.

Essomba, M.A. (2006). Liderar escuelas interculturales e inclusivas: equipos directivos y profesorado ante la diversidad cultural y la inmigración. Barcelona: Grao.

García García, M. (1994). ¿Toda educación es adaptativa? Revista Complutense de Educación, 5(2), 173-182.

García García, M. (2000). Orientaciones para hacer viables las estrategias de adaptación en educación secundaria obligatoria. Revista Española de Orientación y Psicopedagogía, Vol. 11, $n^{\circ}$ 20, 229-240. 
García García, M. (2002).Atención a la diversidad en Educación Secundaria Obligatoria. EduPsykhé, Vol. 1, no 2, 225-248.

García García, M. (2005). Educación Adaptativa y Escuela Inclusiva: una forma de atender las diferencias de todos los estudiantes en C. JIMÉNEZ (coord.). Pedagogía Diferencial. Diversidad y Equidad. 3-31. Madrid: Pearson Educación.

García García, M.; García Corona, D.; Biencinto López, Ch. y González Barbera, C. (2009). De la exclusión a la inclusión: una forma de entender y atender la diversidad cultural en las instituciones escolares. En prensa.

García, M.; Asensio, I.; Biencinto, CH.; García Corona, D.; García Nieto, N.; González, C.; Mafokozi, J; y Ramos, J. (2005-2006). Innovación y eficacia en atención a la diversidad en ESO: ¿qué hace que las experiencias de atención a la diversidad funcionen en los centros de la CAM? Contextos educativos, 8-9, 13-30.

García García, M.; García Corona, D.; García Nieto, N.; Biencinto, CH; Asensio, I y Mafokozi, J. (2007). Análisis diferencial de la problemática generada por los altos índices de alumnado inmigrante en la Comunidad de Madrid. Madrid: Universidad Complutense. Documento inédito.

Goenechea Permisán, C. (2005). La diversidad cultural en la escuela gallega. Problemáticas y alternativas educativas en comunidades con población inmigrante. Santiago de Compostela: Xunta de Galicia.

González Such, J.; Jornet Meliá, J.M.; Suárez Rodríguez, J.M y Pérez Carbonell, A. (1999). Análisis de tipologías de calidad docente a partir de un cuestionario de evaluación del profesorado universitario. Bordón: Revista de Orientación Pedagógica, 51(1), 95-114.
Jiménez Trens, M.A. (2004). El profesorado de la educación secundaria ante la diversidad del alumnado en la etapa obligatoria [Recurso electrónico]. Madrid: Universidad Complutense de Madrid, Servicio de Publicaciones.

Kaiser, H.F. (1960). The application of electronic computers to factor analysis. Educational Psycholy Measurement, v. 20, 141151.

Nunnelly, J.C. (1978). Psychometrics theory. New York: McGraw Hill.

Ramos Santana, G. y Jornet Meliá, J.M. (2006). Diseño y análisis de viabilidad de estándares para la evaluación de la eficiencia/funcionalidad del diseño de programas de teleformación. Bordón: Revista de Orientación Pedagógica, 58(3), 359-377.

Sandoval, M.; López, M.L.; Miquel, E.; Duran, D.; Giné, C.; Echeita, G. (2002). Index for inclusion. Una guía para la evaluación y mejora de la educación inclusiva, Contextos Educativos, 5, 227-238.

\section{NOTAS}

1. Cabe resaltar la inestimable colaboración de todos los centros que colaboraron en el pilotaje y especialmente la ayuda y disposición prestadas por la Subdirección General de Inspección Educativa de la Comunidad de Madrid

2. Si alpha es mayor que 0,9 , el instrumento de medición es excelente; en el intervalo 0,90,8 , el instrumento es bueno; entre $0,8-0,7$, el instrumento es aceptable; en el intervalo 0,70,6 , el instrumento es débil; entre $0,6-0,5$, el instrumento es pobre; y si es menor que 0,5 , no es aceptable. 


\section{ANEXO I: CUESTIONARIO ORIGINAL CUESTIONARIO SOBRE ATENCIÓN A LA DIVERSIDAD}

El objetivo de este cuestionario es el poder llegar a detectar aquellos aspectos que dentro de la Atención a la Diversidad son percibidos como básicos y que favorecen el rendimiento de los alumnos.

Usted, junto con el resto de personas que constituyen el centro, es parte fundamental para conocer dichos aspectos, y por ello necesitamos conocer su opinión.

Le animamos a que conteste y que lo haga con la máxima sinceridad posible.

\section{INSTRUCCIONES DE CUMPLIMENTACIÓN}

En el cuestionario que le presentamos puede ver dos partes. En la primera tratamos de recoger datos generales de su centro y de usted.

En la segunda hay una serie de afirmaciones. Queremos que lea cada una de ellas y que marque con una "X" la casilla que mejor refleje su opinión y si es el caso valore con una escala de 0 a 5 su grado de acuerdo/desacuerdo con dichas afirmaciones.

Si por cualquier motivo se da cuenta que ha marcado una casilla que no es realmente la que quería, no pasa nada, tacha esa "X" y vuelve a poner otra en la casilla que refleja su verdadera opinión.

\section{DATOS PERSONALES}

1. Sexo Hombre $\square$ Mujer $\square$

2. Edad (años)

3. Experiencia profesional

Menos de 5 años

Entre 5 y 10 años

Entre 11 y 15 años $\square$

Más de 15 años

4. Titulación académica

Diplomatura en

Licenciatura en

Doctorado en

5. ¿Ha recibido formación específica en Atención a la Diversidad?

SI $\square \quad$ NO $\square$

Si su respuesta es afirmativa, señale en que ámbito:

Atención en discapacidad auditiva

Atención en discapacidad visual

Atención en discapacidad motórica

Atención en discapacidad lingüística

Atención en discapacidad auditiva

Atención en discapacidad cognitiva

Atención en discapacidad socio-afectiva

Atención en diferencias de origen socio-cultural

Otros

\section{DATOS DEL CENTRO}

6. Nombre del centro

7. Titularidad

Público

Concertado

Privado 
8. Localización (Comunidad Autónoma)
Andalucía
Comunidad Valenciana
Comunidad de Madrid

9. Población del municipio donde está ubicado el centro

Menos de 5.000 habitantes

De 5.001 a 10.000 habitantes

De 10.001 a 50.000 habitantes

De 50.001 a 100.000 habitantes

De 100.001 a 500.000 habitantes

Más de 500.000 habitantes

10. Tamaño del centro

Menos de 300 alumnos

Entre 301 y 650 alumnos

Más de 650 alumnos

11. Etapas que oferta el centro

Educación Infantil

Educación Primaria

Educación Secundaria Obligatoria

Bachillerato

Formación Profesional

12. ¿Es un Centro de Acción Educativa Singular?

$$
\text { SI } \square \text { NO }
$$

13. Modalidades de escolarización

Grupo ordinario a tiempo completo

Grupo ordinario con apoyo en periodo variable

Aula de Educación Especial

Aulas específicas

14. Número de alumnos por aula (ratio)

\section{DATOS SOBRE LA PROCEDENCIA DEL ALUMNADO}

15. Tipo de alumnado

Número de alumnos españoles de padres españoles

Número de alumnos españoles de padres españoles de etnia gitana

Número de alumnos españoles con uno de los progenitores español y el otro extranjero

Numero de alumnos españoles de padres extranjeros

Número de alumnos extranjeros con uno de los progenitores español y el otro extranjero

Número de alumnos extranjeros de padres extranjeros.

16. Del conjunto de alumnos extranjeros, indique el número de años que llevan residiendo en España...

De 0 a 3 años (número de alumnos)

De 4 a 7 años (número de alumnos)

De 8 a 11 años (número de alumnos)

Más de 11 años (número de alumnos) 
17. Procedencia del alumnado extranjero del centro...

Europa del este

Resto de Europa

(número de alumnos)

América Latina

(número de alumnos)

Resto de América

(número de alumnos)

África (MAGREB) (número de alumnos)

África Subsahariana (número de alumnos)

Asia

Otros (número de alumnos) (número de alumnos) (número de alumnos)

\section{CARACTERÍSTICAS DEL ALUMNADO CON NECESIDADES EDUCATIVAS ESPECIALES}

18. Alumnado con Necesidades Educativas Especiales

Capacidad Cognitiva

Capacidad Auditiva

(número de alumnos)

Capacidad Visual

Capacidad Comunicativa-lingüística

(número de alumnos)

Capacidad Socio-afectiva

Capacidad Sensorial

Capacidad Motórica

Autismo y trastornos graves de personalidad (número de alumnos) (número de alumnos)

Plurideficiencia

Superdotados o de altas capacidades (número de alumnos) (número de alumnos) (número de alumnos) (número de alumnos) (número de alumnos) (número de alumnos)

19. Señale si en su centro existen o no y, en caso afirmativo, el grado en el que se utilizan o se han utilizado los siguientes recursos o programas de Atención a la Diversidad.

\begin{tabular}{|c|c|c|c|c|c|c|c|c|}
\hline \multirow[t]{2}{*}{ RECURSOS } & \multicolumn{2}{|c|}{ EXISTENCIA } & \multirow{2}{*}{$\begin{array}{c}\begin{array}{c}\text { No se } \\
\text { utiliza }\end{array} \\
0 \\
\end{array}$} & \multirow{2}{*}{$\begin{array}{c}\begin{array}{c}\text { Muy } \\
\text { poco }\end{array} \\
1 \\
\end{array}$} & \multirow{2}{*}{$\begin{array}{c}\text { Poco } \\
2 \\
\end{array}$} & \multirow{2}{*}{$\frac{\text { Bastante }}{3}$} & \multirow{2}{*}{$\begin{array}{c}\text { Mucho } \\
4 \\
\end{array}$} & \multirow{2}{*}{$\begin{array}{c}\begin{array}{c}\text { Siempre } \\
\text { se utiliza }\end{array} \\
5\end{array}$} \\
\hline & SI & NO & & & & & & \\
\hline $\begin{array}{l}\text { Apoyo del profesor en el aula para alumnos con dificultades en } \\
\text { alguna asignatura concreta }\end{array}$ & & & & & & & & \\
\hline $\begin{array}{l}\text { Nueve horas del horario lectivo en un grupo específico (lengua y } \\
\text { matemáticas) }\end{array}$ & & & & & & & & \\
\hline Diecinueve horas semanales en un grupo específico & & & & & & & & \\
\hline Aulas de compensación educativa & & & & & & & & \\
\hline $\begin{array}{l}\text { Desdoble de grupos en función de los distintos niveles de rendi- } \\
\text { miento }\end{array}$ & & & & & & & & \\
\hline Carga horaria adicional de una asignatura & & & & & & & & \\
\hline $\begin{array}{l}\text { Planes de Acción Tutorial para acoger e integrar a los inmigran- } \\
\text { tes }\end{array}$ & & & & & & & & \\
\hline Apoyo al profesorado para la atención al alumno inmigrante & & & & & & & & \\
\hline $\begin{array}{l}\text { Servicio de traductores en ocasiones puntuales y traducción de } \\
\text { documentos en distintos idiomas }\end{array}$ & & & & & & & & \\
\hline $\begin{array}{l}\text { Servicio de Apoyo Educativo Domiciliario para alumnos que } \\
\text { pasan largos periodos de convalecencia en su domicilio }\end{array}$ & & & & & & & & \\
\hline Hospital de día-Centro Educativo Terapéutico & & & & & & & & \\
\hline Monitores de apoyo al alumnado inmigrante & & & & & & & & \\
\hline $\begin{array}{l}\text { Educadores de calle como apoyo al alumnado dentro y fuera del } \\
\text { centro escolar }\end{array}$ & & & & & & & & \\
\hline $\begin{array}{l}\text { Mediador intercultural que realiza tareas de enlace entre la fami- } \\
\text { lia inmigrante y el centro }\end{array}$ & & & & & & & & \\
\hline $\begin{array}{l}\text { Apoyo del profesor en el aula para alumnos con dificultades en } \\
\text { alguna asignatura concreta }\end{array}$ & & & & & & & & \\
\hline
\end{tabular}




\section{RECURSOS}

\begin{tabular}{|c|c|c|c|c|c|c|c|c|}
\hline \multirow[t]{2}{*}{ RECURSOS } & \multicolumn{2}{|c|}{ EXISTENCIA } & \multirow{2}{*}{$\begin{array}{c}\text { No se } \\
\text { utiliza } \\
0\end{array}$} & \multirow{2}{*}{$\begin{array}{c}\text { Muy } \\
\text { poco }\end{array}$} & \multirow{2}{*}{$\begin{array}{c}\text { Poco } \\
2\end{array}$} & \multirow{2}{*}{$\begin{array}{l}\text { Bastante } \\
3\end{array}$} & \multirow{2}{*}{$\begin{array}{c}\text { Mucho } \\
4\end{array}$} & \multirow{2}{*}{$\begin{array}{c}\begin{array}{c}\text { Siempre } \\
\text { se } \\
\text { utiliza }\end{array} \\
5\end{array}$} \\
\hline & SI & No & & & & & & \\
\hline $\begin{array}{l}\text { Programa de apoyo al estudio para evitar el fracaso escolar reali- } \\
\text { zado por monitores o por los profesores del centro }\end{array}$ & & & & & & & & \\
\hline Programa de ocio y tiempo libre organizado por el centro & & & & & & & & \\
\hline Apoyo de ONGs del entorno & & & & & & & & \\
\hline $\begin{array}{l}\text { Aula de castellanización para mejorar las competencias lingüísti- } \\
\text { cas de los alumnos }\end{array}$ & & & & & & & & \\
\hline Alumnos-ayudantes, del mismo u otro curso & & & & & & & & \\
\hline Programas de acogida, grupos de acogida o planes de acogida & & & & & & & & \\
\hline Grupos de mediación & & & & & & & & \\
\hline Programas de Diversificación Curricular (PDC) & & & & & & & & \\
\hline $\begin{array}{l}\text { Programa de Adaptación Curricular en Grupo (PACG) para } \\
\text { alumnos de } 3^{\circ} \text { de la ESO que presentan un retraso escolar mani- } \\
\text { fiesto }\end{array}$ & & & & & & & & \\
\hline Programas de absentismo escolar & & & & & & & & \\
\hline Programas de hábitos sociales y autonomía personal & & & & & & & & \\
\hline Programas de acceso al mundo laboral & & & & & & & & \\
\hline Programa de educación en valores & & & & & & & & \\
\hline $\begin{array}{l}\text { Adaptaciones curriculares significativas (modificación o elimina- } \\
\text { ción de elementos del currículo) }\end{array}$ & & & & & & & & \\
\hline $\begin{array}{l}\text { Adaptaciones curriculares de acceso: provisión de recursos espe- } \\
\text { ciales que permitan desarrollar el currículo ordinario }\end{array}$ & & & & & & & & \\
\hline Programas de optatividad & & & & & & & & \\
\hline $\begin{array}{l}\text { Programas de flexibilización: para alumnos con NEE por super- } \\
\text { dotación }\end{array}$ & & & & & & & & \\
\hline Vinculación con Centros Externos de Recursos & & & & & & & & \\
\hline $\begin{array}{l}\text { Respeto de la ratio establecida en la norma legal en el aula con } \\
\text { alumnos con NEE }\end{array}$ & & & & & & & & \\
\hline $\begin{array}{l}\text { Atención de alumnos con discapacidad auditiva e intérprete de } \\
\text { Lengua de Signos }\end{array}$ & & & & & & & & \\
\hline Sin barreras arquitectónicas/accesibilidad & & & & & & & & \\
\hline Trasporte escolar adaptado & & & & & & & & \\
\hline Ayudas técnicas necesarias para el alumno con NEE & & & & & & & & \\
\hline $\begin{array}{l}\text { Las plazas y vacantes de profesionales que intervienen con los } \\
\text { alumnos con discapacidad están ocupadas por personal especiali- } \\
\text { zado }\end{array}$ & & & & & & & & \\
\hline $\begin{array}{l}\text { Profesionales especializados: pedagogos, psicopedagogos o } \\
\text { psicólogos }\end{array}$ & & & & & & & & \\
\hline $\begin{array}{l}\text { Equipo para el apoyo educativo al alumno con discapacidad } \\
\text { visual }\end{array}$ & & & & & & & & \\
\hline $\begin{array}{l}\text { Equipo para el apoyo educativo al alumno con discapacidad } \\
\text { motórica }\end{array}$ & & & & & & & & \\
\hline $\begin{array}{l}\text { Equipo para el apoyo educativo al alumno con discapacidad } \\
\text { auditiva }\end{array}$ & & & & & & & & \\
\hline Proyectos de Innovación financiados para atender a la diversidad & & & & & & & & \\
\hline
\end{tabular}


20. Las siguientes afirmaciones hacen referencia a distintos aspectos relacionados con la Atención a la Diversidad, valore su grado de acuerdo/desacuerdo (0 total desacuerdo a 5 total acuerdo), tanto desde una perspectiva personal como desde la perspectiva del centro en el que trabaja.

\begin{tabular}{|c|c|c|c|c|c|c|c|c|c|c|c|c|}
\hline \multirow{2}{*}{ CENTRO } & \multicolumn{6}{|c|}{ Opinión personal } & \multicolumn{6}{|c|}{ Perspectiva de centro } \\
\hline & 0 & 1 & 2 & 3 & 4 & 5 & 0 & 1 & 2 & 3 & 4 & 5 \\
\hline Trabajamos bajo la filosofía de la co-educación & & & & & & & & & & & & \\
\hline Existen atenciones educativas diferenciadas & & & & & & & & & & & & \\
\hline Todos los alumnos son tratados de forma diferente & & & & & & & & & & & & \\
\hline $\begin{array}{l}\text { Los alumnos promocionan de manera diferente en función de sus capaci- } \\
\text { dades }\end{array}$ & & & & & & & & & & & & \\
\hline $\begin{array}{l}\text { Trabajamos para proporcionar ocasiones a todos los alumnos para que } \\
\text { logren los objetivos }\end{array}$ & & & & & & & & & & & & \\
\hline $\begin{array}{l}\text { En ocasiones flexibilizamos los grupos en función de la actividad o estilo } \\
\text { de aprendizaje }\end{array}$ & & & & & & & & & & & & \\
\hline Los alumnos se agrupan según el nivel curricular en el que se encuentran & & & & & & & & & & & & \\
\hline $\begin{array}{l}\text { Dirigimos a los alumnos a opciones profesionales y/o académicas diferen- } \\
\text { tes según su capacidad }\end{array}$ & & & & & & & & & & & & \\
\hline
\end{tabular}

\section{CENTRO}

Todo el centro participa de un proyecto común y una organización inclusiva para que todos los alumnos logren los objetivos

Todos los alumnos están clasificados en función de su nivel de adaptación al sistema educativo

Los métodos y las estrategias educativas están adaptadas a cada estudiante El equipo directivo es flexible para adaptarse a diferentes situaciones

Consideramos que el sistema debe adaptarse al estudiante para compensar sus carencias

En la organización se contemplan tiempos comunes sin alumnos para la coordinación del profesorado

Los espacios se distribuyen según las necesidades concretas del aula

Los recursos se distribuyen según las necesidades concretas del aula

\begin{tabular}{|l|l|l|l|l|l||l|l|l|l|l|l|}
\hline 0 & 1 & 2 & 3 & 4 & 5 & 0 & 1 & 2 & 3 & 4 & 5 \\
\hline
\end{tabular}

\section{CONCEPTO DE NORMALIDAD}

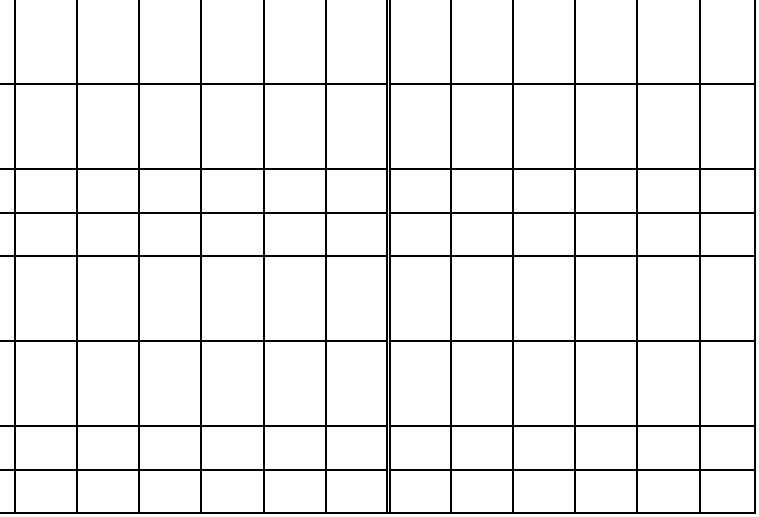

El concepto de normalidad coincide con la idea que tenemos del alumno tipo

En la escuela la normalidad es un reflejo de la sociedad heterogénea

En la escuela la normalidad es la diferencia

Todos los alumnos que no han sido diagnosticados psicopedagógicamente son considerados normales

Todos los alumnos sin excepción se consideran dentro de la norma con sus puntos fuertes y débiles 


\section{CONCEPTO DE DIVERSIDAD}

La diversidad es todo aquello que está fuera de la norma

Los alumnos diversos constituyen grupos diferentes que llevan asociadas sus diferencias a desventajas educativas

La diversidad es algo positivo y enriquecedor

La diversidad lleva consigo la dificultad de adaptarse a la norma

Los tipos de diversidad se crean en función de las necesidades educativas que

requieren los alumnos

Las diferencias siempre son individuales

Las necesidades educativas son propias de los alumnos

La escuela asume como propias las necesidades de sus alumnos

La diversidad está asociada a la idea de dar mas tiempo al que lo necesite

La diversidad esta asociada a las dificultades de aprendizaje

INTERVENCIÓN DEL CENTRO FRENTE A LA DIVER-
SIDAD

Una vez detectadas las diferencias, se agrupa a los estudiantes en función de las mismas

Una vez detectadas las diferencias, todos los alumnos permanecen en el mismo grupo contando con los apoyos y adaptaciones necesarias

Una vez detectadas las diferencias, los alumnos se agrupan de manera flexible en función del objetivo de la actividad o nivel del estudiante, alternando grupos heterogéneos y homogéneos

Se intenta integrar a los alumnos con NEE con el fin de adaptarlos al sistema educativo

\begin{tabular}{lllllll||l|l|l|l|l|}
\hline & & & & & & & & & & & \\
\hline \\
\hline
\end{tabular}

\begin{tabular}{|c|c|c|c|c|c|c|c|c|c|c|c|c|}
\hline \multirow{2}{*}{ DIAGNÓSTICO DE LOS ALUMNOS } & \multicolumn{6}{|c|}{ Opinión personal } & \multicolumn{6}{|c|}{ Perspectiva de centro } \\
\hline & 0 & 1 & 2 & 3 & 4 & 5 & 0 & 1 & 2 & 3 & 4 & 5 \\
\hline \multicolumn{13}{|l|}{$\begin{array}{l}\text { El diagnóstico de los alumnos se basa en sus capacidades cognitivas básicas } \\
\text { para hacer grupos diferenciados }\end{array}$} \\
\hline \multicolumn{13}{|l|}{$\begin{array}{l}\text { El diagnóstico de los alumnos se basa en sus necesidades cognitivas y actitu- } \\
\text { dinales }\end{array}$} \\
\hline \multicolumn{13}{|l|}{$\begin{array}{l}\text { El diagnóstico de los alumnos se basa en diferentes y múltiples aspectos } \\
\text { relacionados con el éxito académico }\end{array}$} \\
\hline \multicolumn{13}{|l|}{$\begin{array}{l}\text { Es necesario identificar a los alumnos con problemas con el fin de desviarles } \\
\text { de la vía ordinaria }\end{array}$} \\
\hline \multicolumn{13}{|l|}{$\begin{array}{l}\text { Es necesario identificar a los alumnos con el fin de asignarles el tratamiento } \\
\text { más adecuado }\end{array}$} \\
\hline \multicolumn{13}{|l|}{$\begin{array}{l}\text { Es necesario identificar las aptitudes y estilos que permiten alcanzar los } \\
\text { objetivos con el fin de utilizar estrategias docentes adecuadas }\end{array}$} \\
\hline \multicolumn{13}{|l|}{$\begin{array}{l}\text { Diagnosticar es fundamental para distinguir entre alumnos dentro de la nor- } \\
\text { ma y alumnos especiales }\end{array}$} \\
\hline \multicolumn{13}{|l|}{$\begin{array}{l}\text { El diagnóstico es fundamental para clasificar a los alumnos y de esta forma } \\
\text { atender a sus necesidades educativas }\end{array}$} \\
\hline $\begin{array}{l}\text { El diagnóstico es fundamental para identificar las diferencias y poder así } \\
\text { ajustar el tratamiento }\end{array}$ & & & & & & & & & & & & \\
\hline
\end{tabular}




\section{CURRICULUM}

El currículo es el mismo para todos incluyendo las adaptaciones necesarias para obtener unos objetivos mínimos

El currículo tiene un núcleo central y común para todos y permite mucha optatividad para crear diferentes itinerarios

Los alumnos diferentes se encuentran en aulas con personal especializado

Los alumnos diferentes permanecen en el mismo aula que el resto con apoyo especializado

Los currículos se adaptan a las necesidades puntuales de las situaciones gracias al trabajo cooperativo de los equipos multidisciplinares

La comunidad educativa asume la atención a los alumnos con discapacidad, contemplándose en el proyecto educativo y curricular del centro

\section{NIVEL DE RENDIMIENTO DE LOS ALUMNOS}

\begin{tabular}{|c|c|c|c|c|c|c|c|c|c|c|c|}
\hline \multicolumn{4}{|c|}{ Opinión personal } & \multicolumn{5}{|c|}{ Perspectiva de centro } \\
\hline $\mathbf{0}$ & 1 & 2 & 3 & 4 & 5 & $\mathbf{0}$ & $\mathbf{1}$ & 2 & 3 & 4 & 5 \\
\hline
\end{tabular}

Los niveles de rendimiento son considerados como algo impuesto desde fuera $\mathrm{y}$ difícil de modificar

Los niveles de logro se adaptan según las necesidades del grupo

El rendimiento o progreso de cada alumno únicamente está en función de sus propias capacidades y del ajuste del programa a las mismas

Existen claras diferencias entre las competencias adquiridas por diferentes vías aunque todos titulen

Los objetivos básicos a alcanzar son los mismos para todos los alumnos

Existen objetivos básicos y comunes para todos así como objetivos individuales

para cada alumno

\begin{tabular}{|l|l|l|l|l|l|l|l|l|l|l|l|l|}
\hline . & & & & & & & & & & & & \\
\hline & & & & & & & & & & & & \\
\hline
\end{tabular}

21. Si usted considera que hay algún aspecto que no queda reflejado en este cuestionario le proporcionamos un espacio para ello.

MUCHAS GRACIAS POR SU COLABORACIÓN 


\section{ANEXO II: CUESTIONARIOS DEFINITIVOS POR AUDIENCIAS Análisis de Variables de Contexto: ATENCIÓN A LA DIVERSIDAD DOCENTES ENERO 2008}

\section{Presentación}

El objetivo de este cuestionario es el poder llegar a detectar aquellos aspectos que dentro de la Atención a la Diversidad son percibidos como básicos y que favorecen el rendimiento de los alumnos.

\section{Instrucciones de Aplicación}

En el cuestionario que le presentamos puede ver dos partes. En la primera tratamos de recoger datos generales de su centro y de usted. En la segunda hay una serie de afirmaciones.

Queremos que lea cada una de ellas y que marque con una "X" la casilla que mejor refleje su opinión y si es el caso rodee con un "O" la valoración (en una escala de 1 a 6) que mejor exprese su grado de acuerdo con cada afirmación. Si por cualquier motivo se da cuenta que ha marcado una casilla que no es realmente la que quería, no pasa nada, tache esa "X" y vuelva a poner otra en la casilla que refleja su verdadera opinión.

La escala de valoración utilizada en cada ocasión aparece antes del apartado o pregunta.

\section{Datos de Identificación}

\begin{tabular}{|l|l|l|l|l|l|}
\hline $\begin{array}{l}\text { Nombre del centro } \\
\text { Nirección del } \\
\text { centro }\end{array}$ & $\begin{array}{l}\text { Comunidad au- } \\
\text { tónoma }\end{array}$ & \\
\hline Tipo de Centro & Público & Concertado & & Privado \\
\hline Número de alumnos en su aula (Ratio) & \\
\hline Número de alumnos con diversidad social en su aula & & \\
\hline
\end{tabular}

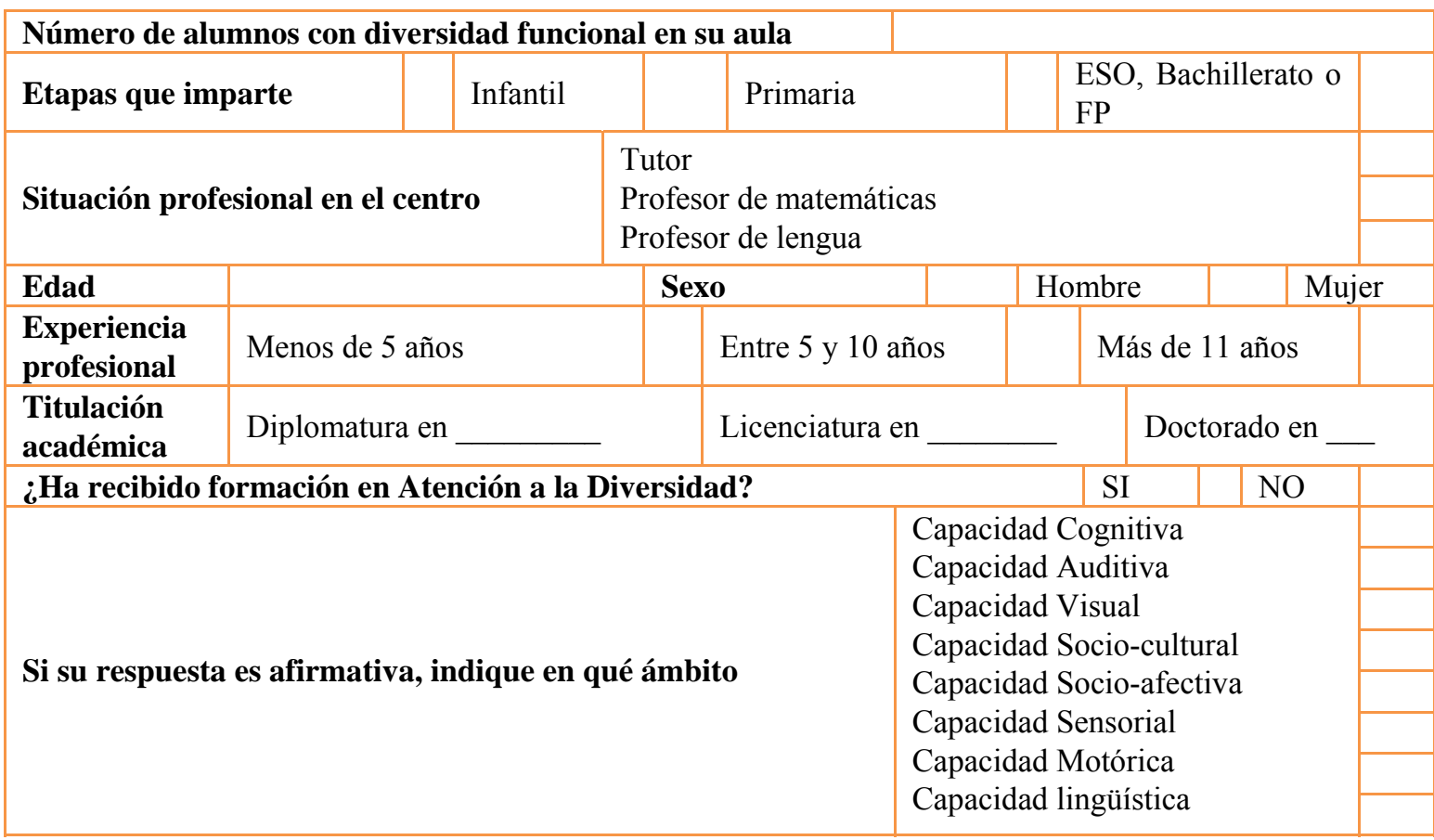


Las siguientes afirmaciones hacen referencia a distintos aspectos relacionados con la Atención a la Diversidad, valore su grado de acuerdo/desacuerdo (1 nada a 6 totalmente), tanto desde una perspectiva personal como desde la perspectiva del centro en el que trabaja.

Escala de Valoración

\begin{tabular}{|c|c|c|c|c|c|c|c|c|c|c|}
\hline 1 & $\begin{array}{l}\text { Nada / } \\
\text { Nunca }\end{array}$ & $\begin{array}{l}\text { Muy Poco / } \\
\text { Casi nunca }\end{array}$ & 3 & $\begin{array}{l}\text { Algo / } \\
\text { Pocas veces }\end{array}$ & 4 & $\begin{array}{l}\text { Bastante/ } \\
\text { Con frecuencia }\end{array}$ & 5 & $\begin{array}{l}\text { Mucho / } \\
\text { Muchas veces }\end{array}$ & 6 & $\begin{array}{l}\text { Totalmente / } \\
\text { Siempre }\end{array}$ \\
\hline
\end{tabular}

\begin{tabular}{|c|c|c|c|c|c|c|c|c|c|}
\hline ÍTEM & RECURSOS & \multicolumn{2}{|c|}{ EXISTENCIA } & \multicolumn{6}{|c|}{ FRECUENCIA DE USO } \\
\hline 1 & $\begin{array}{l}\text { Apoyo del profesor en el aula para alumnos con dificultades en alguna } \\
\text { asignatura concreta }\end{array}$ & SI & NO & 1 & 2 & 3 & 4 & 5 & 6 \\
\hline 2 & Aulas de compensación educativa & SI & NO & 1 & 2 & 3 & 4 & 5 & 6 \\
\hline 3 & Desdoble de grupos en función de los distintos niveles de rendimiento & SI & NO & 1 & 2 & 3 & 4 & 5 & 6 \\
\hline 4 & Planes de Acción Tutorial para acoger e integrar a los inmigrantes & SI & NO & 1 & 2 & 3 & 4 & 5 & 6 \\
\hline 5 & Apoyo al profesorado para la atención al alumno inmigrante & SI & NO & 1 & 2 & 3 & 4 & 5 & 6 \\
\hline 6 & Monitores de apoyo al alumnado inmigrante & SI & NO & 1 & 2 & 3 & 4 & 5 & 6 \\
\hline 7 & $\begin{array}{l}\text { Educadores de calle como apoyo al alumnado dentro y fuera del centro } \\
\text { escolar }\end{array}$ & SI & NO & 1 & 2 & 3 & 4 & 5 & 6 \\
\hline 8 & $\begin{array}{l}\text { Mediador intercultural que realiza tareas de enlace entre la familia inmi- } \\
\text { grante y el centro }\end{array}$ & SI & NO & 1 & 2 & J & 4 & 5 & 6 \\
\hline 9 & $\begin{array}{l}\text { Apoyo del profesor en el aula para alumnos con dificultades en alguna } \\
\text { asignatura concreta }\end{array}$ & SI & NO & 1 & 2 & J & 4 & 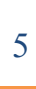 & 6 \\
\hline
\end{tabular}

\begin{tabular}{|c|c|c|c|c|c|c|c|c|c|}
\hline ÍTEM & RECURSOS & \multicolumn{2}{|c|}{ EXISTENCIA } & \multicolumn{6}{|c|}{ FRECUENCIA DE USO } \\
\hline 10 & $\begin{array}{l}\text { Programa de apoyo al estudio para evitar el fracaso escolar realizado por } \\
\text { monitores o por los profesores del centro }\end{array}$ & SI & NO & 1 & 2 & 3 & 4 & 5 & 6 \\
\hline 11 & Alumnos-ayudantes, del mismo u otro curso & SI & NO & 1 & 2 & 3 & 4 & 5 & 6 \\
\hline 12 & Programas de acogida, grupos de acogida o planes de acogida & SI & NO & 1 & 2 & 3 & 4 & 5 & 6 \\
\hline 13 & Grupos de mediación & SI & NO & 1 & 2 & 3 & 4 & 5 & 6 \\
\hline 14 & Programas de absentismo escolar & SI & NO & 1 & 2 & 3 & 4 & 5 & 6 \\
\hline 15 & Programas de hábitos sociales y autonomía personal & SI & NO & 1 & 2 & 3 & 4 & 5 & 6 \\
\hline 16 & $\begin{array}{l}\text { Programas de optatividad: específicos para el desarrollo de competencias } \\
\text { e intereses }\end{array}$ & SI & NO & 1 & 2 & 3 & 4 & 5 & 6 \\
\hline 17 & Programas de flexibilización: para alumnos con NEE por superdotación & SI & NO & 1 & 2 & 3 & 4 & 5 & 6 \\
\hline 18 & Vinculación con Centros Externos de Recursos & SI & NO & 1 & 2 & 3 & 4 & 5 & 6 \\
\hline 19 & $\begin{array}{l}\text { Las plazas y vacantes de profesionales que intervienen con los alumnos } \\
\text { con discapacidad están ocupadas por personal especializado }\end{array}$ & SI & NO & 1 & 2 & 3 & 4 & 5 & 6 \\
\hline 20 & Profesionales especializados: pedagogos, psicopedagogos o psicólogos & SI & NO & 1 & 2 & 3 & 4 & 5 & 6 \\
\hline 21 & Proyectos de Innovación financiados para atender a la diversidad & SI & NO & 1 & 2 & 3 & 4 & 5 & 6 \\
\hline 22 & Formación que responda a las necesidades del profesorado & SI & NO & 1 & 2 & 3 & 4 & 5 & 6 \\
\hline
\end{tabular}

\begin{tabular}{|c|c|c|c|c|c|c|c|c|c|c|c|c|}
\hline ÍTEM & CENTRO & \multicolumn{5}{|c|}{ OPINIÓN PERSONAL } & \multicolumn{6}{|c|}{$\begin{array}{l}\text { PERSPECTIVA DE } \\
\text { CENTRO }\end{array}$} \\
\hline 23 & Trabajamos bajo la filosofía de la co-educación & 12 & & 4 & 5 & & 1 & 2 & 3 & 4 & 5 & \\
\hline 24 & Existen atenciones educativas diferenciadas & 12 & 3 & 4 & 5 & 6 & 1 & 2 & 3 & 4 & 5 & 6 \\
\hline 25 & $\begin{array}{l}\text { Los alumnos promocionan de manera diferente en función de sus } \\
\text { capacidades }\end{array}$ & 12 & 3 & 4 & 5 & 6 & 1 & 2 & 3 & 4 & 5 & 6 \\
\hline 26 & $\begin{array}{l}\text { Trabajamos para proporcionar ocasiones a todos los alumnos para } \\
\text { que logren los objetivos }\end{array}$ & 12 & 3 & 4 & 5 & 6 & 1 & 2 & 3 & 4 & 5 & 6 \\
\hline 27 & $\begin{array}{l}\text { En ocasiones flexibilizamos los grupos en función de la actividad o } \\
\text { estilo de aprendizaje }\end{array}$ & 12 & 3 & 4 & 5 & 6 & 1 & 2 & 3 & 4 & 5 & 6 \\
\hline 28 & $\begin{array}{l}\text { Orientamos a los alumnos a opciones profesionales y/o académicas } \\
\text { diferentes según su capacidad }\end{array}$ & 12 & 3 & 4 & 5 & 6 & 1 & 2 & 3 & 4 & 5 & 6 \\
\hline
\end{tabular}




\begin{tabular}{|c|c|c|c|c|c|c|c|c|c|c|c|c|c|}
\hline ÍTEM & CENTRO & \multicolumn{5}{|c|}{ OPINIÓN PERSONAL } & & \multicolumn{6}{|c|}{$\begin{array}{l}\text { PERSPECTIVA DE } \\
\text { CENTRO }\end{array}$} \\
\hline 29 & $\begin{array}{l}\text { Todo el centro participa de un proyecto común y una organización } \\
\text { inclusiva para que todos los alumnos logren los objetivos }\end{array}$ & & & & 5 & & & I & & 3 & 4 & 5 & 6 \\
\hline 30 & $\begin{array}{l}\text { Los métodos y las estrategias educativas están adaptadas a cada } \\
\text { estudiante }\end{array}$ & 12 & 3 & 4 & 5 & 5 & & & & 3 & 4 & 5 & 6 \\
\hline
\end{tabular}

Escala de Valoración

\begin{tabular}{|c|c|c|c|c|c|c|c|c|c|}
\hline 1 & $\begin{array}{l}\text { Nada / } \\
\text { Nunca }\end{array}$ & $\begin{array}{l}\text { Muy Poco / } \\
\text { Casi nunca }\end{array}$ & $\begin{array}{l}\text { Algo / Pocas } \\
\text { veces }\end{array}$ & 4 & $\begin{array}{l}\text { Bastante/Con } \\
\text { frecuencia }\end{array}$ & 5 & $\begin{array}{l}\text { Mucho / Mu- } \\
\text { chas veces }\end{array}$ & 6 & $\begin{array}{l}\text { Totalmente / } \\
\text { Siempre }\end{array}$ \\
\hline
\end{tabular}

\begin{tabular}{|ll|}
\hline ITEM & \multicolumn{1}{|c|}{ CONCEPTO DE DIVERSIDAD } \\
\hline 32 & La diversidad es algo positivo y enriquecedor \\
\hline 33 & $\begin{array}{l}\text { Los tipos de diversidad se crean en función de las necesidades } \\
\text { educativas que presentan los alumnos }\end{array}$ \\
\hline 34 & Las diferencias siempre son individuales \\
\hline
\end{tabular}

\begin{tabular}{|c|c|c|c|c|c|c|c|c|c|c|c|}
\hline \multicolumn{6}{|c|}{ OPINIÓN PERSONAL } & \multicolumn{6}{|c|}{$\begin{array}{l}\text { PERSPECTIVA DE } \\
\text { CENTRO }\end{array}$} \\
\hline 1 & 2 & & 4 & 5 & & 1 & 2 & 3 & 4 & 5 & 6 \\
\hline 1 & 2 & 3 & 4 & 5 & 6 & 1 & 2 & 3 & 4 & 5 & 6 \\
\hline 1 & 2 & 3 & 4 & 5 & 6 & 1 & 2 & 3 & 4 & 5 & 6 \\
\hline 1 & 2 & 3 & 4 & 5 & 6 & 1 & 2 & 3 & 4 & 5 & 6 \\
\hline
\end{tabular}

\begin{tabular}{|c|c|c|c|c|c|c|c|c|c|c|c|c|c|c|}
\hline ITEM & CURRICULUM & \multicolumn{6}{|c|}{ OPINIÓN PERSONAL } & \multicolumn{7}{|c|}{$\begin{array}{l}\text { PERSPECTIVA DE } \\
\text { CENTRO }\end{array}$} \\
\hline 35 & $\begin{array}{l}\text { El currículo es el mismo para todos incluyendo las adaptaciones } \\
\text { necesarias para obtener unos objetivos mínimos }\end{array}$ & 1 & & 3 & 4 & 5 & & 1 & 2 & 3 & & & 5 & 6 \\
\hline 36 & $\begin{array}{l}\text { El currículo tiene un núcleo central y común para todos y permi- } \\
\text { te mucha optatividad para crear diferentes itinerarios }\end{array}$ & 1 & 2 & 3 & 4 & 5 & 6 & 1 & 2 & 3 & & 4 & 5 & 6 \\
\hline 37 & $\begin{array}{l}\text { Los alumnos diferentes permanecen en el mismo aula que el } \\
\text { resto con apoyo especializado }\end{array}$ & 1 & 2 & 3 & 4 & 5 & 6 & 1 & 2 & 3 & & 4 & 5 & 6 \\
\hline 38 & $\begin{array}{l}\text { Los alumnos diferentes se encuentran en aulas con personal } \\
\text { especializado }\end{array}$ & 1 & 2 & 3 & 4 & 5 & 6 & 1 & 2 & 3 & & 4 & 5 & 6 \\
\hline 39 & $\begin{array}{l}\text { Los currículos se adaptan a las necesidades puntuales de las } \\
\text { situaciones gracias al trabajo cooperativo de los equipos multi- } \\
\text { disciplinares }\end{array}$ & 1 & 2 & 3 & 4 & 5 & 6 & 1 & 2 & 3 & & 4 & 5 & 6 \\
\hline 40 & $\begin{array}{l}\text { La comunidad educativa asume la atención a los alumnos con } \\
\text { discapacidad, contemplándose en el proyecto educativo y curri- } \\
\text { cular del centro }\end{array}$ & 1 & 2 & 3 & 4 & 3 & 6 & 1 & 2 & & & 4 & 5 & 6 \\
\hline
\end{tabular}

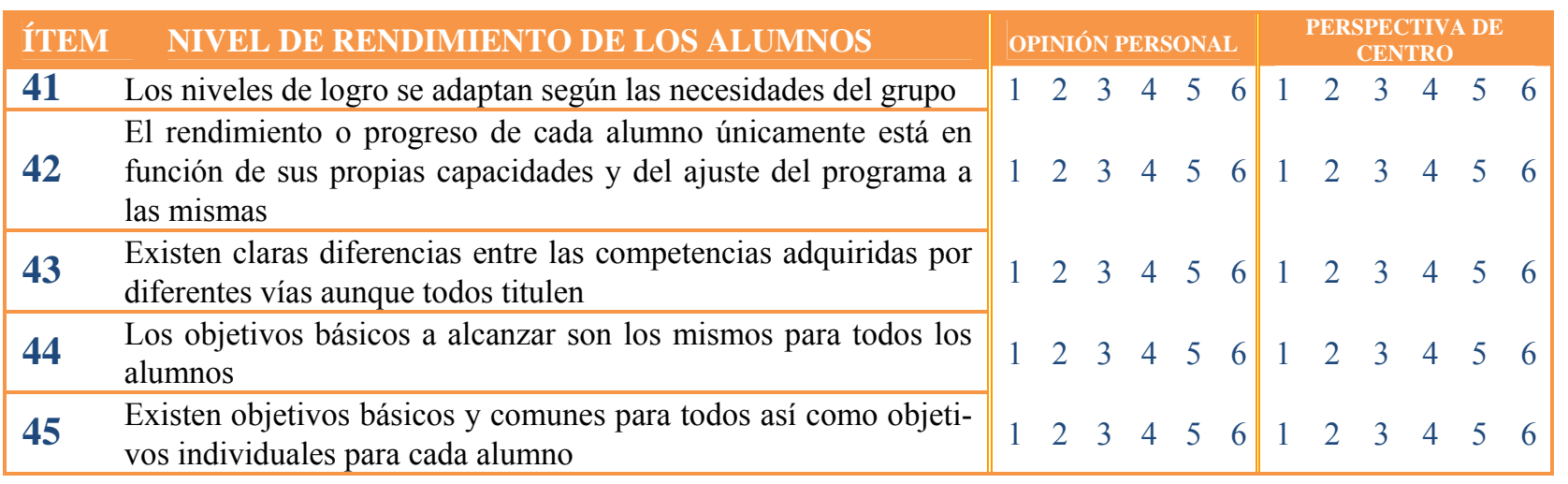

Si usted considera que hay algún aspecto que no queda reflejado en este cuestionario le proporcionamos un espacio para ello 


\section{Análisis de Variables de Contexto: ATENCIÓN A LA DIVERSIDAD ORIENTADORES/AS Y/O APOYO DIVERSIDAD ENERO 2008}

Presentación

El objetivo de este cuestionario es el poder llegar a detectar aquellos aspectos que dentro de la Atención a la Diversidad son percibidos como básicos y que favorecen el rendimiento de los alumnos.

\section{Instrucciones de Aplicación}

En el cuestionario que le presentamos puede ver dos partes. En la primera tratamos de recoger datos generales de su centro y de usted. En la segunda hay una serie de afirmaciones.

Queremos que lea cada una de ellas y que marque con una " $\mathrm{X}$ " la casilla que mejor refleje su opinión y si es el caso rodee con un "O" la valoración (en una escala de 1 a 6) que mejor exprese su grado de acuerdo con cada afirmación. Si por cualquier motivo se da cuenta que ha marcado una casilla que no es realmente la que quería, no pasa nada, tache esa " $X$ " y vuelva a poner otra en la casilla que refleja su verdadera opinión.

La escala de valoración utilizada en cada ocasión aparece antes del apartado o pregunta.

\section{Datos de Identificación}

\begin{tabular}{|c|c|c|c|c|c|}
\hline \multicolumn{6}{|l|}{ Nombre del centro } \\
\hline \multirow{2}{*}{$\begin{array}{l}\text { Dirección del centro } \\
\text { Tipo de Centro }\end{array}$} & & & $\begin{array}{l}\text { Comunidad } \\
\text { Autónoma }\end{array}$ & \multirow{2}{*}{\multicolumn{2}{|c|}{ Privado }} \\
\hline & Público & Concertado & & & \\
\hline \multicolumn{4}{|c|}{ ¿Tiene elaborado el centro un Plan de Atención a la Diversidad? } & SI & NO \\
\hline
\end{tabular}

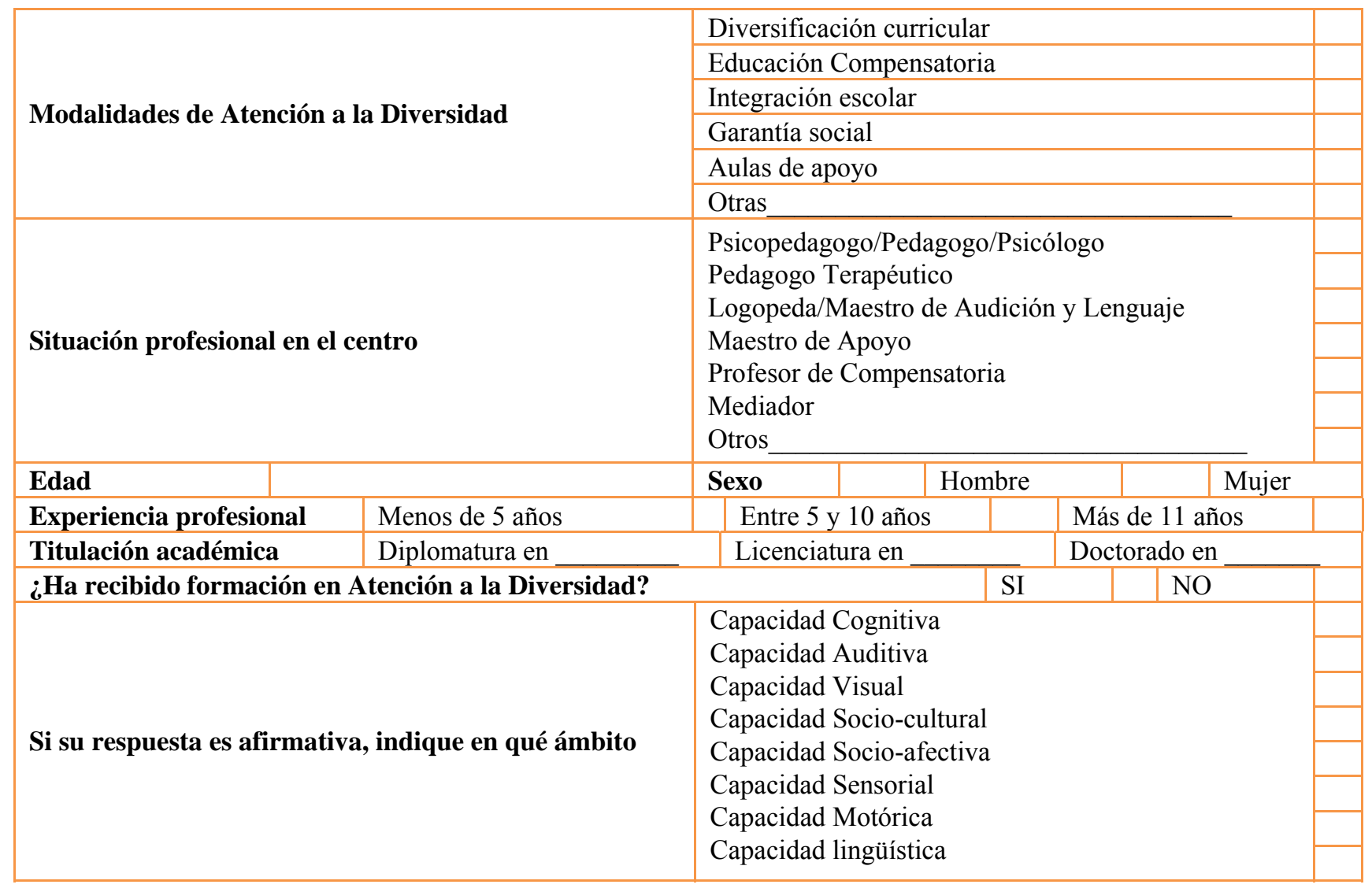




\section{Datos sobre la procedencia del alumnado}

\begin{tabular}{|c|c|c|c|c|c|}
\hline & & & OS R & $\begin{array}{l}\text { SIDI } \\
\text { SPAÑ }\end{array}$ & DO EN \\
\hline & & $0-3$ & $4-7$ & $8-11$ & $\begin{array}{l}\text { Más de } \\
11\end{array}$ \\
\hline & $\begin{array}{l}\text { Europa del este } \\
\text { Resto de Europa }\end{array}$ & & & & \\
\hline & América Latina & & & & \\
\hline Procedencia del alumnado & Resto de América & & & & \\
\hline & Africa (MAGREB) & & & & \\
\hline & & & & & \\
\hline & & & & & \\
\hline & & & & & \\
\hline
\end{tabular}

\section{Número de alumnos con Necesidades Educativas Especiales}

Capacidad Cognitiva

Capacidad Auditiva

Capacidad Visual

Capacidad Comunicativa-lingüística

Capacidad Socio-afectiva

Capacidad Sensorial

Capacidad Motórica

Autismo y trastornos graves de personalidad

Plurideficiencia

Superdotados o de altas capacidades

Las siguientes afirmaciones hacen referencia a distintos aspectos relacionados con la Atención a la Diversidad, valore su grado de acuerdo/desacuerdo (1 nada a 6 totalmente), tanto desde una perspectiva personal como desde la perspectiva del centro en el que trabaja.

Escala de Valoración

\begin{tabular}{|c|c|c|c|}
\hline $\begin{array}{l}\text { Nada / } \\
\text { Nunca }\end{array}$ & I & $\begin{array}{l}\text { Muy Poco / } \\
\text { Casi nunca }\end{array}$ & 3 \\
\hline
\end{tabular}

\begin{tabular}{|c|c|c|c|c|c|c|c|c|c|}
\hline ÍTEM & RECURSOS & \multicolumn{2}{|c|}{ EXISTENCIA } & \multicolumn{6}{|c|}{ FRECUENCIA DE USO } \\
\hline 1 & $\begin{array}{l}\text { Apoyo del profesor en el aula para alumnos con dificultades en alguna } \\
\text { asignatura concreta }\end{array}$ & SI & NO & 1 & 2 & 3 & 4 & 5 & 6 \\
\hline 2 & Aulas de compensación educativa & SI & $\mathrm{NO}$ & 1 & 2 & 3 & 4 & 5 & 6 \\
\hline 3 & Desdoble de grupos en función de los distintos niveles de rendimiento & SI & NO & 1 & 2 & 3 & 4 & 5 & 6 \\
\hline 4 & Planes de Acción Tutorial para acoger e integrar a los inmigrantes & SI & NO & 1 & 2 & 3 & 4 & 5 & 6 \\
\hline 5 & Apoyo al profesorado para la atención al alumno inmigrante & SI & $\mathrm{NO}$ & 1 & 2 & 3 & 4 & 5 & 6 \\
\hline 6 & Monitores de apoyo al alumnado inmigrante & SI & NO & 1 & 2 & 3 & 4 & 5 & 6 \\
\hline 7 & $\begin{array}{l}\text { Educadores de calle como apoyo al alumnado dentro y fuera del centro } \\
\text { escolar }\end{array}$ & SI & $\mathrm{NO}$ & 1 & 2 & 3 & 4 & 5 & 6 \\
\hline 8 & $\begin{array}{l}\text { Mediador intercultural que realiza tareas de enlace entre la familia inmi- } \\
\text { grante y el centro }\end{array}$ & SI & $\mathrm{NO}$ & 1 & 2 & 5 & 4 & 5 & 6 \\
\hline 9 & $\begin{array}{l}\text { Apoyo del profesor en el aula para alumnos con dificultades en alguna } \\
\text { asignatura concreta }\end{array}$ & SI & $\mathrm{NO}$ & 1 & 2 & 3 & 4 & 5 & 6 \\
\hline
\end{tabular}




\begin{tabular}{|c|c|c|c|c|c|c|c|c|c|}
\hline ÍTEM & RECURSOS & \multicolumn{2}{|c|}{ EXISTENCIA } & \multicolumn{6}{|c|}{ FRECUENCIA DE USO } \\
\hline 10 & $\begin{array}{l}\text { Programa de apoyo al estudio para evitar el fracaso escolar realizado por } \\
\text { monitores o por los profesores del centro }\end{array}$ & SI & NO & 1 & & 3 & 4 & 5 & 6 \\
\hline 11 & Alumnos-ayudantes, del mismo u otro curso & SI & NO & 1 & 2 & 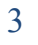 & 4 & 5 & 6 \\
\hline 12 & Programas de acogida, grupos de acogida o planes de acogida & SI & NO & 1 & 2 & 3 & 4 & 5 & 6 \\
\hline 13 & Grupos de mediación & SI & NO & 1 & 2 & 3 & 4 & 5 & 6 \\
\hline 14 & Programas de absentismo escolar & SI & NO & 1 & 2 & 3 & 4 & 5 & 6 \\
\hline
\end{tabular}

Escala de Valoración

\begin{tabular}{l|l|l|l|l|l|l|l|l|l}
1 & $\begin{array}{l}\text { Nada } \\
\text { Nunca }\end{array}$ & $\begin{array}{l}\text { Muy Poco / } \\
\text { Casi nunca }\end{array}$ & $\begin{array}{l}\text { Algo / Pocas } \\
\text { veces }\end{array}$ & $4 \begin{array}{l}\text { Bastante/Con } \\
\text { frecuencia }\end{array}$ & $5 \begin{array}{l}\text { Mucho / Mu- } \\
\text { chas veces }\end{array}$ & $\begin{array}{l}\text { Totalmente / } \\
\text { Siempre }\end{array}$ \\
\hline
\end{tabular}

\begin{tabular}{|c|c|c|c|c|c|c|c|c|c|}
\hline ÍTEM & RECURSOS & \multicolumn{2}{|c|}{ EXISTENCIA } & \multicolumn{6}{|c|}{$\begin{array}{l}\text { PERSPECTIVA DE } \\
\text { CENTRO }\end{array}$} \\
\hline 15 & Programas de hábitos sociales y autonomía personal & SI & NO & 1 & 2 & 3 & 4 & & \\
\hline 16 & $\begin{array}{l}\text { Programas de optatividad: específicos para el desarrollo de competencias } \\
\text { e intereses }\end{array}$ & SI & NO & 1 & 2 & 3 & 4 & 5 & 6 \\
\hline 17 & Programas de flexibilización: para alumnos con NEE por superdotación & SI & NO & 1 & 2 & 3 & 4 & 5 & 6 \\
\hline 18 & Vincula & SI & NO & 1 & 2 & 3 & 4 & 5 & 6 \\
\hline 19 & $\begin{array}{l}\text { Las plazas y vacantes de profesionales que intervienen con los alumnos } \\
\text { con discapacidad están ocupadas por personal especializado }\end{array}$ & SI & NO & 1 & 2 & 3 & 4 & 5 & 6 \\
\hline 20 & gos, psicopedagogos o psicólogos & SI & NO & 1 & 2 & 3 & 4 & 5 & 6 \\
\hline 21 & a atender a la divers & SI & NO & 1 & 2 & 3 & 4 & 5 & \\
\hline 22 & Formación que responda a las necesidades del profesorado & SI & NO & 1 & 2 & 3 & 4 & 5 & \\
\hline
\end{tabular}

\begin{tabular}{|c|c|c|c|c|c|c|c|c|c|c|c|c|}
\hline ÍTEM & CENTRO & \multicolumn{5}{|c|}{ OPINIÓN PERSONAL } & \multicolumn{6}{|c|}{$\begin{array}{l}\text { PERSPECTIVA DE } \\
\text { CENTRO }\end{array}$} \\
\hline 23 & Trabajamos bajo la filosofía de la co-educación & 12 & 3 & 4 & 5 & & 1 & 2 & 3 & 4 & 5 & 0 \\
\hline 24 & Existen atenciones educativas diferenciadas & 12 & 3 & 4 & 5 & 6 & 1 & 2 & 3 & 4 & 5 & 6 \\
\hline 25 & $\begin{array}{l}\text { Los alumnos promocionan de manera diferente en función de sus } \\
\text { capacidades }\end{array}$ & 12 & 3 & 4 & 5 & 6 & 1 & 2 & 3 & 4 & 5 & 6 \\
\hline 26 & $\begin{array}{l}\text { Trabajamos para proporcionar ocasiones a todos los alumnos para } \\
\text { que logren los objetivos }\end{array}$ & 12 & 3 & 4 & 5 & 6 & 1 & 2 & 3 & 4 & 5 & 6 \\
\hline 27 & $\begin{array}{l}\text { En ocasiones flexibilizamos los grupos en función de la actividad o } \\
\text { estilo de aprendizaje }\end{array}$ & 12 & 3 & 4 & 5 & 6 & 1 & 2 & 3 & 4 & 5 & 6 \\
\hline 28 & $\begin{array}{l}\text { Orientamos a los alumnos a opciones profesionales y/o académicas } \\
\text { diferentes según su capacidad }\end{array}$ & 12 & 3 & $\boldsymbol{T}$ & 5 & 6 & 1 & 2 & 3 & 4 & 5 & 6 \\
\hline 29 & $\begin{array}{l}\text { Todo el centro participa de un proyecto común y una organización } \\
\text { inclusiva para que todos los alumnos logren los objetivos }\end{array}$ & 12 & 3 & 4 & 5 & 6 & 1 & 2 & 3 & 4 & 5 & 6 \\
\hline 30 & $\begin{array}{l}\text { Los métodos y las estrategias educativas están adaptadas a cada } \\
\text { estudiante }\end{array}$ & 1 & 3 & 4 & 5 & 6 & 1 & 2 & 3 & 4 & 5 & 6 \\
\hline
\end{tabular}

\begin{tabular}{|c|c|c|c|c|c|c|c|c|c|c|c|c|}
\hline ITEM & CONCEPTO DE DIVERSIDAD & \multicolumn{5}{|c|}{ OPINIÓN PERSONAL } & \multicolumn{6}{|c|}{$\begin{array}{l}\text { PERSPECTIVA DE } \\
\text { CENTRO }\end{array}$} \\
\hline 31 & La diversidad es algo positivo y enriquecedor & & 3 & 4 & 5 & 56 & & 2 & 3 & & & \\
\hline 32 & $\begin{array}{l}\text { Los tipos de diversidad se crean en función de las necesidades } \\
\text { educativas que presentan los alumnos }\end{array}$ & 1 & 3 & 4 & 5 & 56 & 1 & 2 & 3 & 4 & 5 & 6 \\
\hline 33 & Las diferencias siempre son individuales & 12 & 3 & 4 & 5 & 6 & 1 & 2 & 3 & 4 & 5 & 0 \\
\hline 34 & La escuela asume como propias las necesidades de sus alumnos & 12 & 3 & 4 & 45 & 56 & 1 & 2 & 3 & 4 & 5 & 6 \\
\hline
\end{tabular}


Escala de Valoración

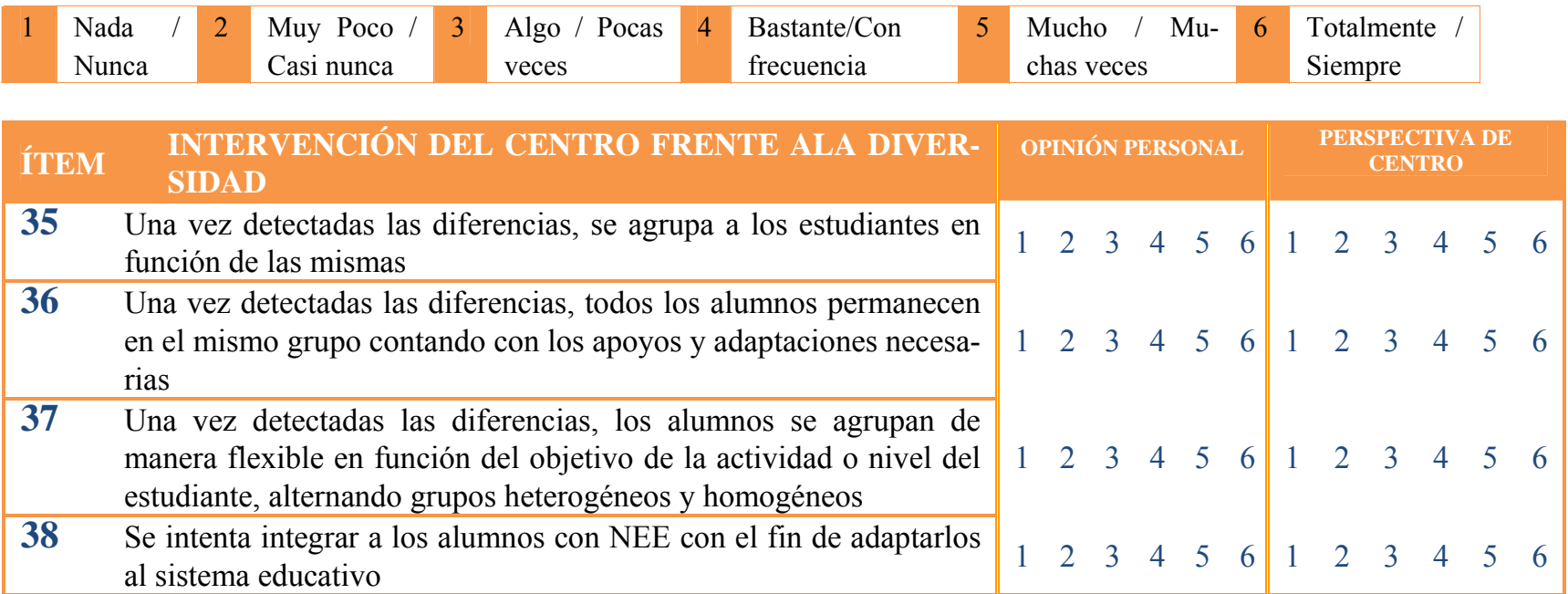

\begin{tabular}{|c|c|c|c|c|c|c|c|c|c|c|c|c|}
\hline ÍTEM & DIAGNÓSTICO & \multicolumn{5}{|c|}{ OPINIÓN PERSONAL } & \multicolumn{6}{|c|}{$\begin{array}{l}\text { PERSPECTIVA DE } \\
\text { CENTRO }\end{array}$} \\
\hline 39 & $\begin{array}{l}\text { El diagnóstico de los alumnos se basa en sus capacidades cogniti- } \\
\text { vas básicas para hacer grupos diferenciados }\end{array}$ & 12 & 3 & 4 & 5 & 6 & 1 & 2 & 3 & 4 & 5 & 6 \\
\hline 40 & $\begin{array}{l}\text { El diagnóstico de los alumnos se basa en sus necesidades cogniti- } \\
\text { vas y actitudinales }\end{array}$ & 12 & 3 & 4 & 5 & 6 & 1 & 2 & 3 & 4 & 5 & 6 \\
\hline 41 & $\begin{array}{l}\text { Es necesario identificar a los alumnos con el fin de asignarles la } \\
\text { respuesta educativa más adecuada }\end{array}$ & 12 & 3 & 4 & 5 & 6 & 1 & 2 & 3 & 4 & 5 & 6 \\
\hline 42 & $\begin{array}{l}\text { Es necesario identificar las aptitudes y estilos que permiten alcan- } \\
\text { zar los objetivos con el fin de utilizar estrategias docentes adecua- } \\
\text { das }\end{array}$ & 12 & 3 & 4 & 5 & 6 & 1 & 2 & 3 & 4 & 5 & 6 \\
\hline 43 & $\begin{array}{l}\text { Diagnosticar es fundamental para distinguir entre alumnos dentro } \\
\text { de la norma y alumnos especiales }\end{array}$ & 12 & 3 & 4 & 5 & 6 & 1 & 2 & 3 & 4 & 5 & 6 \\
\hline 44 & $\begin{array}{l}\text { El diagnóstico es fundamental para agrupar a los alumnos y de esta } \\
\text { forma atender a sus necesidades educativas }\end{array}$ & 12 & 3 & 4 & 5 & 6 & 1 & 2 & 3 & 4 & 5 & 6 \\
\hline 45 & $\begin{array}{l}\text { El diagnóstico es fundamental para identificar las diferencias y } \\
\text { poder así ajustar la respuesta educativa }\end{array}$ & 12 & 3 & 4 & 5 & 6 & 1 & 2 & 3 & 4 & & 6 \\
\hline
\end{tabular}

\begin{tabular}{|c|c|c|c|c|c|c|c|c|c|c|c|c|c|}
\hline ÍTEM & CURRICULUM & \multicolumn{6}{|c|}{ OPINIÓN PERSONAL } & \multicolumn{6}{|c|}{$\begin{array}{l}\text { PERSPECTIVA DE } \\
\text { CENTRO }\end{array}$} \\
\hline 46 & $\begin{array}{l}\text { El currículo es el mismo para todos incluyendo las adaptaciones } \\
\text { necesarias para obtener unos objetivos mínimos }\end{array}$ & 1 & 2 & 3 & 4 & 5 & 6 & 1 & 2 & 3 & 4 & 5 & 6 \\
\hline 47 & $\begin{array}{l}\text { El currículo tiene un núcleo central y común para todos y permite } \\
\text { mucha optatividad para crear diferentes itinerarios }\end{array}$ & 1 & 2 & 3 & 4 & 5 & 6 & 1 & 2 & 3 & 4 & 5 & 6 \\
\hline 48 & $\begin{array}{l}\text { Los alumnos diferentes permanecen en el mismo aula que el resto } \\
\text { con apoyo especializado }\end{array}$ & 1 & 2 & 3 & 4 & 5 & 6 & 1 & 2 & 3 & 4 & 5 & 6 \\
\hline 49 & $\begin{array}{l}\text { Los alumnos diferentes se encuentran en aulas con personal espe- } \\
\text { cializado }\end{array}$ & 1 & 2 & 3 & 4 & 5 & 6 & 1 & 2 & 3 & 4 & 5 & 6 \\
\hline 50 & $\begin{array}{l}\text { Los currículos se adaptan a las necesidades puntuales de las situa- } \\
\text { ciones gracias al trabajo cooperativo de los equipos multidiscipli- } \\
\text { nares }\end{array}$ & 1 & 2 & $J$ & 4 & 5 & 6 & 1 & 2 & 3 & 4 & 5 & 6 \\
\hline 51 & $\begin{array}{l}\text { La comunidad educativa asume la atención a los alumnos con } \\
\text { discapacidad, contemplándose en el proyecto educativo y curricu- } \\
\text { lar del centro }\end{array}$ & 1 & 2 & 5 & 4 & 5 & 6 & 1 & 2 & 3 & 4 & 5 & 0 \\
\hline
\end{tabular}

Si usted considera que hay algún aspecto que no queda reflejado en este cuestionario le proporcionamos un espacio para ello

\section{MUCHAS GRACIAS POR SU COLABORACIÓN}




\title{
Análisis de Variables de Contexto: ATENCIÓN A LA DIVERSIDAD
}

\author{
INSPECTORES/AS ENERO 2008
}

\section{Presentación}

El objetivo de este cuestionario es el poder llegar a detectar aquellos aspectos que dentro de la Atención a la Diversidad son percibidos como básicos y que favorecen el rendimiento de los alumnos.

Le pedimos que rellene un cuestionario por cada centro de los que están bajo su responsabilidad.

Instrucciones de Aplicación

En el cuestionario que le presentamos puede ver dos partes. En la primera tratamos de recoger datos generales del centro y de usted. En la segunda hay una serie de afirmaciones.

Queremos que lea cada una de ellas y que marque con una " $\mathrm{X}$ " la casilla que mejor refleje su opinión y si es el caso rodee con un "O" la valoración (en una escala de 1 a 6) que mejor exprese su grado de acuerdo con cada afirmación. Si por cualquier motivo se da cuenta que ha marcado una casilla que no es realmente la que quería, no pasa nada, tache esa " $X$ " y vuelva a poner otra en la casilla que refleja su verdadera opinión.

La escala de valoración utilizada en cada ocasión aparece antes del apartado o pregunta.

\section{Datos de Identificación.}

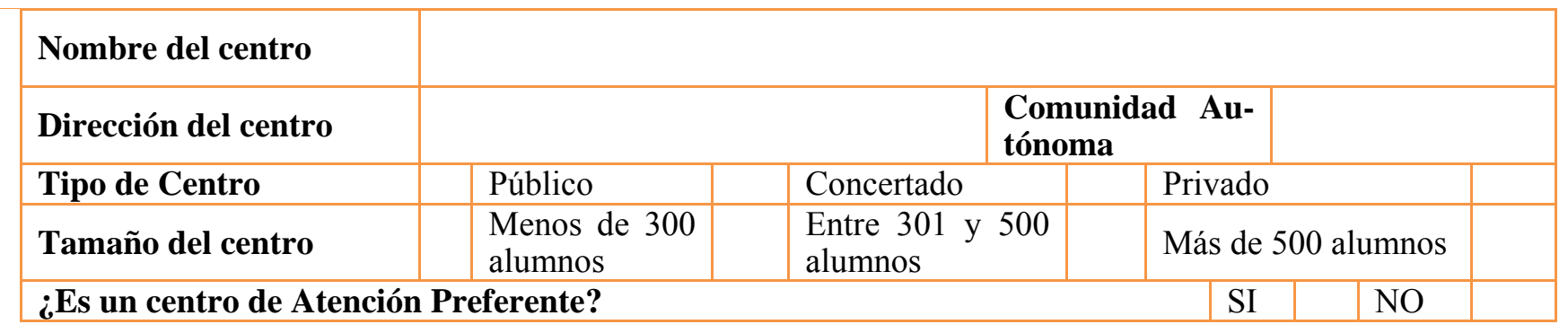

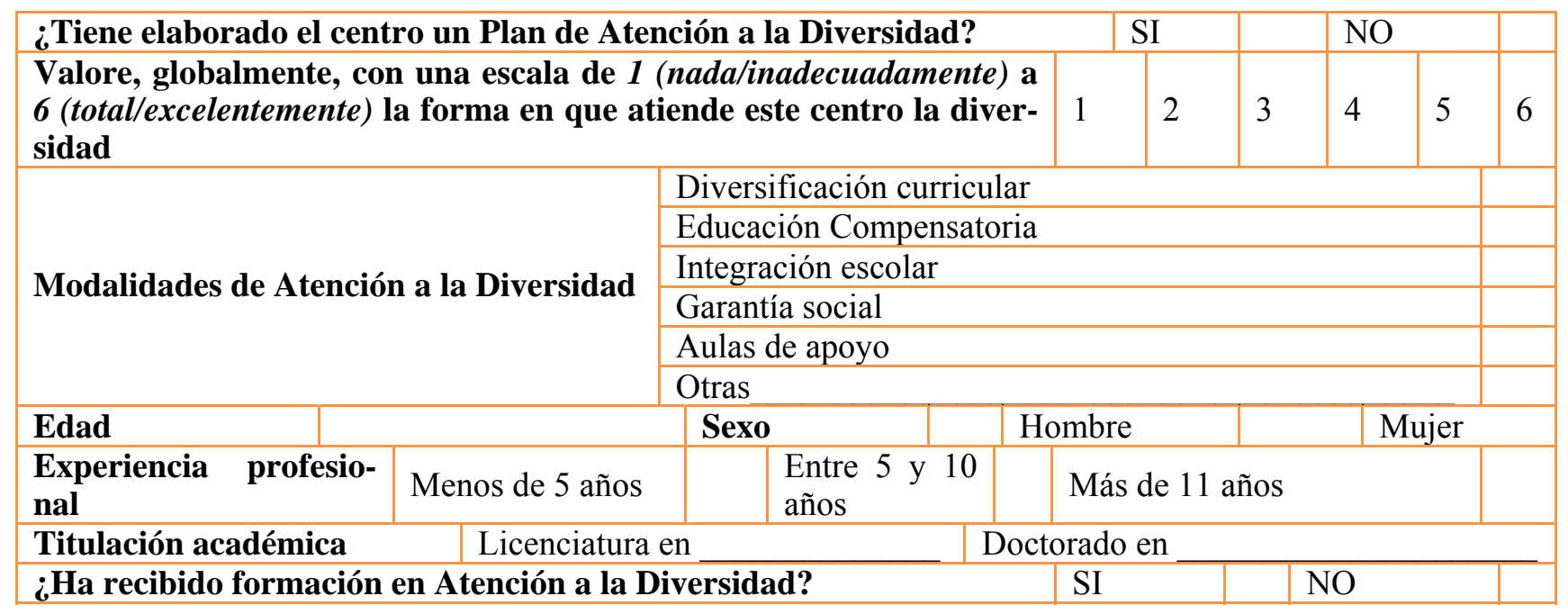




\section{Datos sobre la procedencia del alumnado}

\begin{tabular}{|c|c|c|c|c|c|}
\hline & & AÑ & 2ESII & NDO 1 & SPAÑA \\
\hline & & $0-3$ & $4-7$ & $8-11$ & Más de 11 \\
\hline \multirow{7}{*}{ Procedencia del alumnado } & \multirow{7}{*}{$\begin{array}{l}\text { Europa del este } \\
\text { Resto de Europa } \\
\text { América Latina } \\
\text { Resto de América } \\
\text { África (MAGREB) } \\
\text { África Subsahariana } \\
\text { Asia } \\
\text { Otros.................. }\end{array}$} & & & & \\
\hline & & & & & \\
\hline & & & & & \\
\hline & & & & & \\
\hline & & & & & \\
\hline & & & & & \\
\hline & & & & & \\
\hline
\end{tabular}

Las siguientes afirmaciones hacen referencia a distintos aspectos relacionados con la Atención a la Diversidad, valore su grado de acuerdo/desacuerdo (1 nada a 6 totalmente), tanto desde una perspectiva personal como desde la perspectiva del centro.

Escalla de Valoración

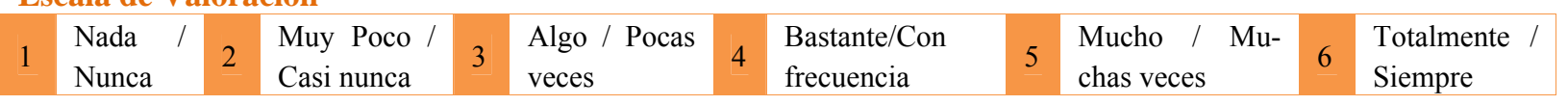

\begin{tabular}{|c|c|c|c|c|c|c|c|c|c|c|c|c|c|}
\hline ÍTEM & CENTRO & \multicolumn{5}{|c|}{ OPINIÓN PERSONAL } & \multicolumn{7}{|c|}{$\begin{array}{l}\text { PERSPECTIVA DE } \\
\text { CENTRO }\end{array}$} \\
\hline 1 & Trabajan bajo la filosofía de la co-educación & 12 & 3 & 4 & 5 & 5 & & 1 & 2 & 3 & 4 & 5 & 6 \\
\hline 2 & Existen atenciones educativas diferenciadas & 12 & 3 & 4 & 5 & 5 & & 1 & 2 & 3 & 4 & 5 & 6 \\
\hline 3 & $\begin{array}{l}\text { Los alumnos promocionan de manera diferente en función de sus } \\
\text { capacidades }\end{array}$ & 12 & 3 & 4 & 5 & 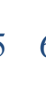 & & 1 & 2 & 3 & 4 & 5 & 6 \\
\hline 4 & $\begin{array}{l}\text { Trabajan para proporcionar ocasiones a todos los alumnos para que } \\
\text { logren los objetivos }\end{array}$ & 12 & 3 & 4 & 5 & 5 & & 1 & 2 & 3 & 4 & 5 & 6 \\
\hline 5 & $\begin{array}{l}\text { En ocasiones flexibilizan los grupos en función de la actividad o } \\
\text { estilo de aprendizaje }\end{array}$ & 12 & 3 & 4 & 5 & ( & & 1 & 2 & 3 & 4 & 5 & 6 \\
\hline 6 & $\begin{array}{l}\text { Orientan a los alumnos a opciones profesionales y/o académicas } \\
\text { diferentes según su capacidad }\end{array}$ & 1 & 3 & 4 & 5 & 5 & & 1 & 2 & 3 & 4 & 5 & 6 \\
\hline 7 & $\begin{array}{l}\text { Todo el centro participa de un proyecto común y una organización } \\
\text { inclusiva para que todos los alumnos logren los objetivos }\end{array}$ & 1 & 3 & 4 & 5 & 5 & & 1 & 2 & 3 & 4 & 5 & 6 \\
\hline 8 & $\begin{array}{l}\text { Los métodos y las estrategias educativas están adaptadas a cada } \\
\text { estudiante }\end{array}$ & 1 & J & 4 & 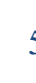 & 5 & & 1 & 2 & 3 & 4 & 5 & 6 \\
\hline 9 & $\begin{array}{l}\text { El equipo directivo es flexible para adaptarse a diferentes situacio- } \\
\text { nes }\end{array}$ & 1 & 3 & 4 & 5 & 5 & & 1 & 2 & 3 & 4 & 5 & 6 \\
\hline
\end{tabular}




\begin{tabular}{|c|c|c|c|c|c|c|c|c|c|c|c|c|}
\hline ÍTEM & CENTRO & \multicolumn{5}{|c|}{ OPINIÓN PERSONAL } & \multicolumn{6}{|c|}{$\begin{array}{l}\text { PERSPECTIVA DE } \\
\text { CENTRO }\end{array}$} \\
\hline 10 & $\begin{array}{l}\text { Consideran que el sistema debe adaptarse al estudiante para com- } \\
\text { pensar sus carencias }\end{array}$ & 12 & 3 & 4 & 5 & 6 & 1 & 2 & 3 & 4 & 5 & 6 \\
\hline 11 & $\begin{array}{l}\text { En la organización se contemplan tiempos comunes sin alumnos } \\
\text { para la coordinación del profesorado }\end{array}$ & 12 & 3 & 4 & 5 & 6 & 1 & 2 & 3 & 4 & 3 & 6 \\
\hline 12 & $\begin{array}{l}\text { Los espacios se distribuyen según las necesidades concretas del } \\
\text { aula }\end{array}$ & 12 & 3 & 4 & 5 & 6 & 1 & 2 & 3 & 4 & 5 & 6 \\
\hline 13 & $\begin{array}{l}\text { Los recursos se distribuyen según las necesidades concretas del } \\
\text { aula }\end{array}$ & 1 & 3 & & 5 & 6 & 1 & 2 & 3 & 4 & & 6 \\
\hline
\end{tabular}

Escala de Valoración

\begin{tabular}{|c|c|c|c|c|c|c|c|c|c|c|c|}
\hline 1 & $\begin{array}{l}\text { Nada / } \\
\text { Nunca }\end{array}$ & 2 & $\begin{array}{l}\text { Muy Poco / } \\
\text { Casi nunca }\end{array}$ & 3 & $\begin{array}{l}\text { Algo / Pocas } \\
\text { veces }\end{array}$ & 4 & $\begin{array}{l}\text { Bastante/Con } \\
\text { frecuencia }\end{array}$ & 5 & $\begin{array}{l}\text { Mucho / Muchas } \\
\text { veces }\end{array}$ & 6 & $\begin{array}{l}\text { Totalmente / } \\
\text { Siempre }\end{array}$ \\
\hline
\end{tabular}

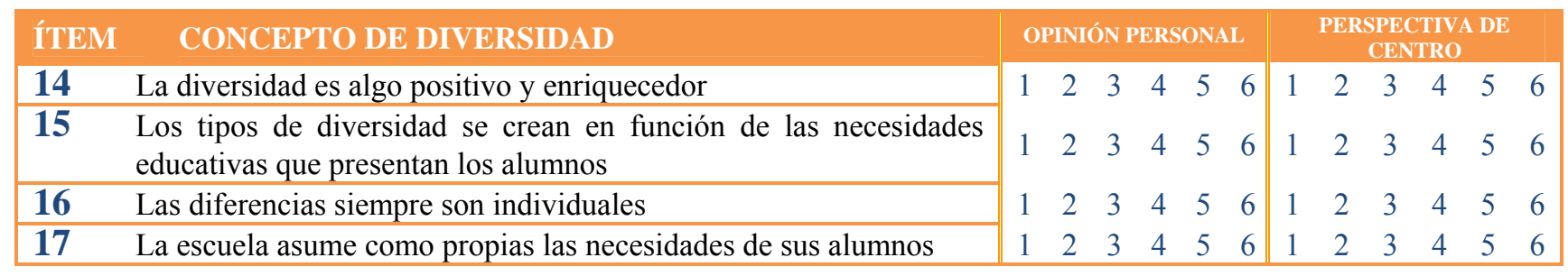

\begin{tabular}{|c|c|c|c|c|c|c|c|c|c|c|c|c|}
\hline ITEM & CURRICULUM & \multicolumn{5}{|c|}{ OPINIÓN PERSONAL } & \multicolumn{6}{|c|}{$\begin{array}{l}\text { PERSPECTIVA DE } \\
\text { CENTRO }\end{array}$} \\
\hline 18 & $\begin{array}{l}\text { El currículo es el mismo para todos incluyendo las adaptaciones } \\
\text { necesarias para obtener unos objetivos mínimos }\end{array}$ & 12 & 3 & 4 & 5 & 6 & 1 & 2 & 3 & 4 & 5 & 6 \\
\hline 19 & $\begin{array}{l}\text { El currículo tiene un núcleo central y común para todos y permite } \\
\text { mucha optatividad para crear diferentes itinerarios }\end{array}$ & 12 & 3 & 4 & 5 & 6 & 1 & 2 & 3 & 4 & 5 & 6 \\
\hline 20 & $\begin{array}{l}\text { Los alumnos diferentes permanecen en el mismo aula que el resto } \\
\text { con apoyo especializado }\end{array}$ & 12 & 3 & 4 & 5 & 6 & 1 & 2 & 3 & 4 & 5 & 6 \\
\hline 21 & $\begin{array}{l}\text { Los alumnos diferentes se encuentran en aulas con personal espe- } \\
\text { cializado }\end{array}$ & 12 & 3 & 4 & 5 & 6 & 1 & 2 & 3 & 4 & 5 & 6 \\
\hline 22 & $\begin{array}{l}\text { Los currículos se adaptan a las necesidades puntuales de las situa- } \\
\text { ciones gracias al trabajo cooperativo de los equipos multidiscipli- } \\
\text { nares }\end{array}$ & 12 & 3 & 4 & 5 & 6 & 1 & 2 & 3 & 4 & 5 & 6 \\
\hline 23 & $\begin{array}{l}\text { La comunidad educativa asume la atención a los alumnos con } \\
\text { diversidad, contemplándose en el proyecto educativo y curricular } \\
\text { del centro }\end{array}$ & 12 & 3 & $T$ & 5 & 6 & 1 & 2 & 3 & & 5 & 6 \\
\hline
\end{tabular}

Si usted considera que hay algún aspecto que no queda reflejado en este cuestionario le proporcionamos un espacio para ello 


\section{Análisis de Variables de Contexto: ATENCIÓN A LA DIVERSIDAD DIRECTORES/AS ENERO 2008}

Presentación

El objetivo de este cuestionario es el poder llegar a detectar aquellos aspectos que dentro de la Atención a la Diversidad son percibidos como básicos y que favorecen el rendimiento de los alumnos.

Instrucciones de Aplicación

En el cuestionario que le presentamos puede ver dos partes. En la primera tratamos de recoger datos generales de su centro y de usted. En la segunda hay una serie de afirmaciones.

Queremos que lea cada una de ellas y que marque con una " $\mathrm{X}$ " la casilla que mejor refleje su opinión y si es el caso rodee con un "O" la valoración (en una escala de 1 a 6) que mejor exprese su grado de acuerdo con cada afirmación. Si por cualquier motivo se da cuenta que ha marcado una casilla que no es realmente la que quería, no pasa nada, tache esa " $X$ " y vuelva a poner otra en la casilla que refleja su verdadera opinión.

La escala de valoración utilizada en cada ocasión aparece antes del apartado o pregunta.

\section{Datos de Identificación}

\begin{tabular}{|l|l|l|l|l|l|}
\hline Nombre del centro & \multicolumn{5}{|l|}{} \\
\hline Dirección del centro & \multicolumn{5}{|l|}{$\begin{array}{l}\text { Comunidad } \\
\text { Autónoma }\end{array}$} \\
\hline Tipo de Centro & Público & $\begin{array}{l}\text { Concertado } \\
\text { Privado }\end{array}$ & $\begin{array}{l}\text { Mas de 500 alum- } \\
\text { nos }\end{array}$ \\
\hline Tamaño del centro & $\begin{array}{l}\text { Menos de } \\
300 \text { alumnos }\end{array}$ & $\begin{array}{l}\text { Entre 301 y } \\
500 \text { alumnos }\end{array}$ & $\begin{array}{l}\text { ESO, Bachillerato } \\
\text { o FP }\end{array}$ \\
\hline Etapas que imparte & Infantil & & Primaria & \\
\hline
\end{tabular}

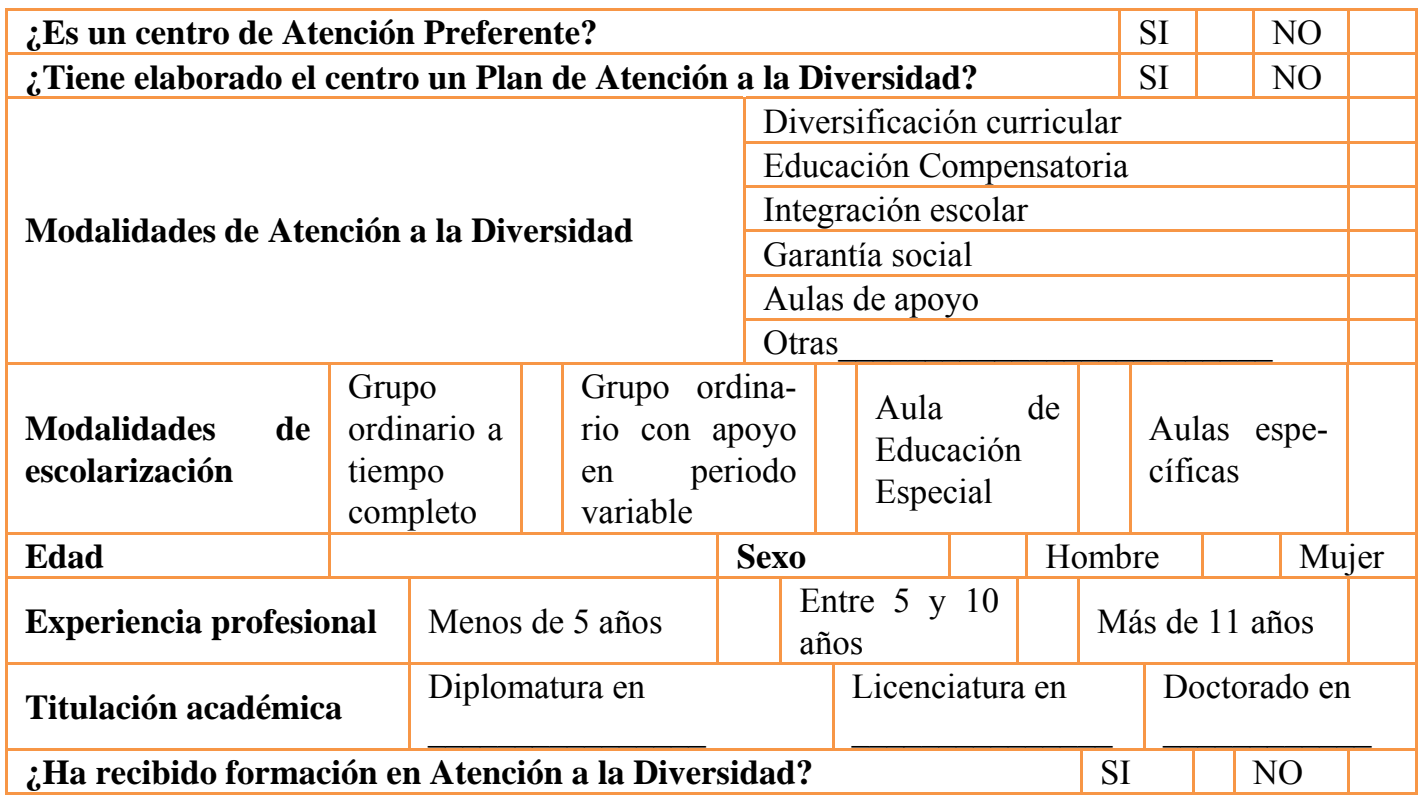




\section{Datos sobre la procedencia del alumnado}

\begin{tabular}{|l|l|l|l|l|}
\cline { 2 - 4 } \multicolumn{1}{|c|}{ AÑOS RESIDIENDO EN ES- } \\
PAÑA
\end{tabular}

\section{Número de alumnos con Necesidades Educativas Especiales}

\begin{tabular}{|l|l|}
\cline { 2 - 2 } \multicolumn{1}{l|}{} & $\mathbf{N}^{\mathrm{a}}$ \\
\cline { 2 - 2 } Capacidad Cognitiva & \\
\cline { 2 - 2 } Capacidad Auditiva & \\
Capacidad Visual & \\
Capacidad Comunicativa-lingüística & \\
\cline { 2 - 2 } Capacidad Socio-afectiva & \\
Capacidad Sensorial & \\
Capacidad Motórica & \\
\cline { 2 - 2 } Autismo y trastornos graves de personalidad & \\
\cline { 2 - 2 } Plurideficiencia & \\
Superdotados o de altas capacidades & \\
\hline
\end{tabular}

Las siguientes afirmaciones hacen referencia a distintos aspectos relacionados con la Atención a la Diversidad, valore su grado de acuerdo/desacuerdo (1 nada a 6 totalmente), tanto desde una perspectiva personal como desde la perspectiva del centro en el que trabaja.

Escala de Valoración

\begin{tabular}{|c|c|c|c|c|c|}
\hline $\begin{array}{l}\text { Nada / } \\
\text { Nunca }\end{array}$ & I & $\begin{array}{l}\text { Muy Poco / } \\
\text { Casi nunca }\end{array}$ & 3 & Algo / & \\
\hline
\end{tabular}

\begin{tabular}{|c|c|c|c|c|c|c|c|c|c|c|c|c|c|}
\hline ÍTEM & CENTRO & \multicolumn{5}{|c|}{ OPINIÓN PERSONAL } & \multicolumn{7}{|c|}{$\begin{array}{l}\text { PERSPECTIVA DE } \\
\text { CENTRO }\end{array}$} \\
\hline 1 & Trabajamos bajo la filosofía de la co-educación & & & 4 & & & 1 & 2 & 3 & & 4 & & \\
\hline 2 & Existen atenciones educativas diferenciadas & 12 & 3 & 4 & 5 & & 1 & 2 & 3 & & 4 & 5 & 6 \\
\hline 3 & $\begin{array}{l}\text { Los alumnos promocionan de manera diferente en función de sus } \\
\text { capacidades }\end{array}$ & 12 & 3 & 4 & 5 & 6 & 1 & 2 & 3 & & 4 & 5 & 6 \\
\hline 4 & $\begin{array}{l}\text { Trabajamos para proporcionar ocasiones a todos los alumnos para } \\
\text { que logren los objetivos }\end{array}$ & 12 & 3 & 4 & 5 & 6 & 1 & 2 & 3 & & 4 & 5 & 6 \\
\hline 5 & $\begin{array}{l}\text { En ocasiones flexibilizamos los grupos en función de la actividad o } \\
\text { estilo de aprendizaje }\end{array}$ & 12 & 3 & 4 & 5 & 6 & 1 & 2 & 3 & & 4 & 5 & 6 \\
\hline 6 & $\begin{array}{l}\text { Orientamos a los alumnos a opciones profesionales y/o académicas } \\
\text { diferentes según su capacidad }\end{array}$ & 12 & 3 & 4 & 5 & 6 & 1 & 2 & 3 & & 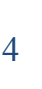 & 5 & 6 \\
\hline 7 & $\begin{array}{l}\text { Todo el centro participa de un proyecto común y una organización } \\
\text { inclusiva para que todos los alumnos logren los objetivos }\end{array}$ & 12 & 3 & $T$ & 5 & & 1 & 2 & 3 & & 4 & 5 & 6 \\
\hline
\end{tabular}




\begin{tabular}{|c|c|c|c|c|c|c|c|c|c|c|c|c|c|}
\hline ÍTEM & CENTRO & \multicolumn{6}{|c|}{ OPINIÓN PERSONAL } & \multicolumn{6}{|c|}{$\begin{array}{l}\text { PERSPECTIVA DE } \\
\text { CENTRO }\end{array}$} \\
\hline 8 & $\begin{array}{l}\text { Los métodos y las estrategias educativas están adaptadas a cada } \\
\text { estudiante }\end{array}$ & 1 & & 3 & 4 & 5 & 6 & 1 & 2 & 3 & 4 & 5 & 6 \\
\hline 9 & $\begin{array}{l}\text { El equipo directivo es flexible para adaptarse a diferentes situacio- } \\
\text { nes }\end{array}$ & 1 & 2 & 3 & 4 & 5 & 6 & 1 & 2 & 3 & 4 & 5 & 6 \\
\hline 10 & $\begin{array}{l}\text { Consideramos que el sistema debe adaptarse al estudiante para } \\
\text { compensar sus carencias }\end{array}$ & 1 & 2 & 3 & 4 & 5 & 6 & 1 & 2 & 3 & 4 & 5 & 6 \\
\hline 11 & $\begin{array}{l}\text { En la organización se contemplan tiempos comunes sin alumnos } \\
\text { para la coordinación del profesorado }\end{array}$ & 1 & 2 & 3 & 4 & 5 & 6 & 1 & 2 & 3 & 4 & 5 & 6 \\
\hline 12 & $\begin{array}{l}\text { Los espacios se distribuyen según las necesidades concretas del } \\
\text { aula }\end{array}$ & 1 & 2 & 3 & T & & 6 & 1 & 2 & 3 & 4 & 5 & 6 \\
\hline 13 & $\begin{array}{l}\text { Los recursos se distribuyen según las necesidades concretas del } \\
\text { aula }\end{array}$ & 1 & 2 & 3 & 4 & & U & 1 & 2 & 3 & 4 & J & 6 \\
\hline
\end{tabular}

\begin{tabular}{|c|c|c|c|c|c|c|c|c|c|c|c|c|c|}
\hline ÍTEM & CONCEPTO DE DIVERSIDAD & \multicolumn{6}{|c|}{ OPINIÓN PERSONAL } & \multicolumn{6}{|c|}{$\begin{array}{l}\text { PERSPECTIVA DE } \\
\text { CENTRO }\end{array}$} \\
\hline 14 & La diversidad es algo positivo y enriquecedor & 1 & 2 & 3 & 4 & 5 & & 1 & 2 & 3 & 4 & 5 & 6 \\
\hline 15 & $\begin{array}{l}\text { Los tipos de diversidad se crean en función de las necesidades } \\
\text { educativas que presentan los alumnos }\end{array}$ & 1 & 2 & 3 & & 5 & 6 & 1 & 2 & 3 & 4 & 5 & 6 \\
\hline 16 & Las diferencias siempre son individuales & 1 & 2 & 3 & 4 & 5 & 6 & 1 & 2 & 3 & 4 & 5 & 6 \\
\hline 17 & La escuela asume como propias las necesidades de sus alumnos & 1 & 2 & 3 & 4 & 5 & 6 & 1 & 2 & 3 & 4 & 5 & 6 \\
\hline
\end{tabular}

\begin{tabular}{|c|c|c|c|c|c|c|c|c|c|c|c|c|c|}
\hline ÍTEM & $\begin{array}{l}\text { INTERVENCIÓN DEL CENTRO FRENTE ALA DIVER- } \\
\text { SIDAD }\end{array}$ & \multicolumn{6}{|c|}{ OPINIÓN PERSONAL } & \multicolumn{6}{|c|}{$\begin{array}{l}\text { PERSPECTIVA DE } \\
\text { CENTRO }\end{array}$} \\
\hline 18 & $\begin{array}{l}\text { Una vez detectadas las diferencias, se agrupa a los estudiantes en } \\
\text { función de las mismas }\end{array}$ & 1 & & 3 & 4 & 5 & 6 & 1 & 2 & 3 & 4 & 5 & 6 \\
\hline 19 & $\begin{array}{l}\text { Una vez detectadas las diferencias, todos los alumnos permanecen } \\
\text { en el mismo grupo contando con los apoyos y adaptaciones necesa- } \\
\text { rias }\end{array}$ & 1 & 2 & 3 & 4 & 5 & 6 & 1 & 2 & 3 & 4 & 5 & 6 \\
\hline 20 & $\begin{array}{l}\text { Una vez detectadas las diferencias, los alumnos se agrupan de } \\
\text { manera flexible en función del objetivo de la actividad o nivel del } \\
\text { estudiante, alternando grupos heterogéneos y homogéneos }\end{array}$ & 1 & 2 & 3 & 4 & 5 & 6 & 1 & 2 & 3 & 4 & 5 & 6 \\
\hline 21 & $\begin{array}{l}\text { Se intenta integrar a los alumnos con NEE con el fin de adaptarlos } \\
\text { al sistema educativo }\end{array}$ & 1 & 2 & 3 & 4 & 5 & 6 & 1 & 2 & 3 & 4 & 5 & 6 \\
\hline
\end{tabular}

\begin{tabular}{|c|c|c|c|c|c|c|c|c|c|c|c|c|}
\hline ITEM & CURRICULUM & \multicolumn{5}{|c|}{ OPINIÓN PERSONAL } & \multicolumn{6}{|c|}{$\begin{array}{l}\text { PERSPECTIVA DE } \\
\text { CENTRO }\end{array}$} \\
\hline 22 & $\begin{array}{l}\text { El currículo es el mismo para todos incluyendo las adaptaciones } \\
\text { necesarias para obtener unos objetivos mínimos }\end{array}$ & 12 & 3 & 4 & 5 & 6 & 1 & 2 & 3 & 4 & 5 & 6 \\
\hline 23 & $\begin{array}{l}\text { El currículo tiene un núcleo central y común para todos y permite } \\
\text { mucha optatividad para crear diferentes itinerarios }\end{array}$ & 12 & 3 & 4 & 5 & 6 & 1 & 2 & 3 & 4 & 5 & 6 \\
\hline 24 & $\begin{array}{l}\text { Los alumnos diferentes permanecen en el mismo aula que el resto } \\
\text { con apoyo especializado }\end{array}$ & 12 & 3 & 4 & 5 & 6 & 1 & 2 & 3 & 4 & 5 & 6 \\
\hline 25 & $\begin{array}{l}\text { Los alumnos diferentes se encuentran en aulas con personal espe- } \\
\text { cializado }\end{array}$ & 12 & 3 & 4 & 5 & 6 & 1 & 2 & 3 & 4 & 5 & 6 \\
\hline 26 & $\begin{array}{l}\text { Los currículos se adaptan a las necesidades puntuales de las situa- } \\
\text { ciones gracias al trabajo cooperativo de los equipos multidiscipli- } \\
\text { nares }\end{array}$ & 12 & 3 & 4 & 5 & 6 & 1 & 2 & 3 & 4 & 5 & 6 \\
\hline 27 & $\begin{array}{l}\text { La comunidad educativa asume la atención a los alumnos con } \\
\text { diversidad, contemplándose en el proyecto educativo y curricular } \\
\text { del centro }\end{array}$ & 12 & 3 & 4 & 5 & 6 & 1 & 2 & 3 & 4 & 5 & 6 \\
\hline
\end{tabular}

Si usted considera que hay algún aspecto que no queda reflejado en este cuestionario le proporcionamos un espacio para ello 
Biencinto-López, Chantal, González-Barbera, Coral, García-García, Mercedes, Sánchez-Delgado, Purificación, Madrid-Vivar, Dolores

(2009). Diseño y propiedades psicométricas del AVACO-EVADIE. Cuestionario para la evaluación de la atención a la diversidad como dimensión educativa en las instituciones escolares. RELIEVE, v. 15, n. 1, 1-36. http://www.uv.es/RELIEVE/v15n1/RELIEVEv15n1 4.htm.

\section{ANEXO III: MATRIZ DE COMPONENTES ROTADOS}

\begin{tabular}{|c|c|c|c|c|c|}
\hline & \multicolumn{5}{|c|}{ Componente } \\
\hline & 1 & 2 & 3 & 4 & 5 \\
\hline La escuela asume como propias las necesidades de sus alumnos & ,744 & & & & \\
\hline La diversidad es algo positivo y enriquecedor & ,687 & & & & \\
\hline Los tipos de diversidad se crean en función de las necesidades educativas que presentan los alumnos & ,663 & & & & \\
\hline $\begin{array}{l}\text { Todo el centro participa de un proyecto común y una organización inclusiva para que todos los alumnos } \\
\text { logren los objetivos }\end{array}$ & ,623 & & ,392 & & \\
\hline Las diferencias siempre son individuales &, 615 & & & ,430 & \\
\hline Trabajamos para proporcionar ocasiones a todos los alumnos para que logren los objetivos &, 612 & & ,354 & & \\
\hline Los alumnos diferentes permanecen en el mismo aula que el resto con apoyo especializado & 603 & & & & \\
\hline Los métodos y las estrategias educativas están adaptadas a cada estudiante. & ,601 & & 462 & & \\
\hline $\begin{array}{l}\text { Los currículos se adaptan a las necesidades puntuales de las situaciones gracias al trabajo cooperativo de } \\
\text { los equipos multidisciplinares }\end{array}$ & ,599 & & & & \\
\hline Existen atenciones educativas diferenciadas & ,550 & & ,405 & & \\
\hline $\begin{array}{l}\text { La comunidad educativa asume la atención a los alumnos con discapacidad, contemplándose en el pro- } \\
\text { yecto educativo y curricular del centro }\end{array}$ & ,543 & & & & \\
\hline Existen objetivos básicos y comunes para todos así como objetivos individuales para cada alumno & 464 & & & & \\
\hline Planes de Acción tutorial para acoger e integrar a los inmigrantes. & & ,812 & & & \\
\hline Proyectos de Innovación financiados para atender a la diversidad & & ,793 & & & \\
\hline Mediador intercultural que realiza tareas de enlace entre la familia inmigrante y el centro & & ,791 & & & \\
\hline Educadores de calle como apoyo al alumnado dentro y fuera del centro escolar & & ,733 & & & \\
\hline Apoyo al profesorado para la atención al alumno inmigrante & & ,688 & & & \\
\hline Monitores de apoyo al alumnado inmigrante & & ,619 & & & \\
\hline Grupos de mediación & & ,528 & ,356 & & \\
\hline Vinculación con Centros Extremos de Recursos & &, 518 & ,394 & ,360 & \\
\hline Aulas de compensación educativa & &, 506 & &,- 326 & \\
\hline Alumnos-ayudantes, del mismo u otro centro & & ,312 & & & \\
\hline Programas de optatividad: específicos para el desarrollo de competencias e intereses & & & ,704 & & \\
\hline Formación que responda a las necesidades del profesorado & & & 649 & & \\
\hline Programas de hábitos sociales y autonomía personal & & & ,619 & & \\
\hline $\begin{array}{l}\text { Programa de apoyo al estudio para evitar el fracaso escolar realizado por monitores o por los profesores } \\
\text { del centro }\end{array}$ & & & ,577 & & \\
\hline $\begin{array}{l}\text { La plazas y vacantes de profesionales que intervienen con los alumnos con discapacidad están ocupadas } \\
\text { por personal especializado }\end{array}$ & & & ,573 & & \\
\hline Programas de flexibilización: para alumnos con NEE por superdotación & & ,463 & 530 & & \\
\hline Orientamos a los alumnos a opciones profesionales y/o académicas diferentes según su capacidad & & & ,529 & & \\
\hline Programas de acogida, grupos de acogida o planes de acogida & & ,320 & 4,461 & & \\
\hline Profesionales especializados: pedagogos, psicopedagogos o psicólogos. & & & 436 & & \\
\hline En ocasiones flexibilizamos los grupos en función de la actividad o estilo de aprendizaje. & 409 & &, 434 & & \\
\hline Desdoble de grupos en función de los distintos niveles de rendimiento & & & 425 & & \\
\hline Apoyo del profesorado en el aula para alumnos con dificultades en alguna asignatura concreta & & & 400 & & \\
\hline Los alumnos promocionan de manera diferente en función de sus capacidades & ,322 & & ,397 & & ,396 \\
\hline Los objetivos básicos a alcanzar son los mismos para todos los alumnos & & & & ,657 & \\
\hline $\begin{array}{l}\text { El currículo es el mismo para todos incluyendo las adaptaciones necesarias para obtener unos objetivos } \\
\text { mínimos }\end{array}$ & & & & ,643 & \\
\hline $\begin{array}{l}\text { El rendimiento o progreso de cada alumno únicamente está en función de sus propias capacidades y del } \\
\text { ajuste del programa a las mismas }\end{array}$ & & & &, 571 & \\
\hline Los niveles de logro se adaptan según las necesidades del grupo & 341 & & & ,381 & \\
\hline Programas de absentismo escolar & & ,348 &, 355 & 360 & \\
\hline Los alumnos diferentes se encuentran en aulas con personal especializado & & & & & ,662 \\
\hline Existen claras diferencias entre las competencias adquiridas por diferentes vías aunque todos titulen & & & & & 549 \\
\hline $\begin{array}{l}\text { El currículo tiene un núcleo central y común para todos y permite mucha optatividad para crear diferentes } \\
\text { itinerarios }\end{array}$ & & & & ,308 &, 322 \\
\hline
\end{tabular}

Método de extracción: Análisis de componentes principales.

Método de rotación: Normalización Varimax con Kaiser. $a$ La rotación ha convergido en 10 iteraciones. 


\section{ABOUT THE AUTHORS / SOBRE LOS AUTORES}

Biencinto-López, Chantal (alameda@edu.ucm.es). Profesora Ayudante Doctora en el Departamento de Métodos de Investigación y Diagnóstico en Educación (MIDE) de la Universidad Complutense de Madrid. Es la autora de contacto para este artículo. Su dirección postal es: Departamento MIDE. Facultad de Educación. C/ Rector Royo Villanova, s/n. 28040-Madrid. Buscar otros artículos de este autor en Scholar Google

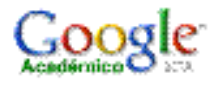

González-Barbera, Coral (cgbarbera@edu.ucm.es).Profesora Ayudante Doctora en el Departamento de Métodos de Investigación y Diagnóstico en Educación (MIDE) de la Universidad Complutense de Madrid. Es especialista en Metodología y Medición en Educación. Su dirección postal es: Departamento MIDE. Facultad de Educación. C/ Rector Royo Villanova, s/n. 28040-Madrid..

$\underline{\text { Buscar otros artículos de este autor en Scholar Google }}$

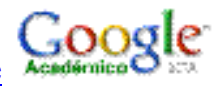

García-García, Mercedes (mergarci@edu.ucm.es). Profesora Titular en el Departamento de Métodos de Investigación y Diagnóstico en Educación (MIDE) de la Universidad Complutense de Madrid. Es especialista en atención a la diversidad en educación. Su dirección postal es: Departamento MIDE. Facultad de Educación. C/ Rector Royo Villanova, s/n. 28040-Madrid. Buscar otros artículos de este autor en Scholar Google

\section{Google}

Sánchez-Delgado, Purificación (Purificacion.Sanchez@uv.es). Profesora Asociada en el Departamento de Métodos de Investigación y Diagnóstico en Educación (MIDE) de la Universidad de Valencia. Es especialista en evaluación y medición. Su dirección postal es: Departamento MIDE. Facultad de Filosofía y Ciencias de la Educación. Avda. Blasco Ibáñez, 30. 46010-Valencia. Buscar $\underline{\text { otros artículos de este autor en Scholar Google }}$

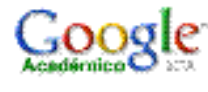

Madrid-Vivar, Dolores (1madrid@uma.es). Profesora Ayudante en el Departamento de Métodos de Investigación e innovación Educativa de la Universidad de Málaga. Es especialista en Educación Infantil y Nuevas Tecnologías aplicadas a la Educación. Buscar otros artículos de este autor en Scho$\underline{\text { lar Google }}$ Google 
Biencinto-López, Chantal, González-Barbera, Coral, García-García, Mercedes, Sánchez-Delgado, Purificación, Madrid-Vivar, Dolores (2009). Diseño y propiedades psicométricas del AVACO-EVADIE. Cuestionario para la evaluación de la atención a la diversidad como dimensión educativa en las instituciones escolares. RELIEVE, v. 15, n. 1, 1-36. http://www.uv.es/RELIEVE/v15n1/RELIEVEv15n1 4.htm.

\section{ARTICLE RECORD / FICHA DEL ARTÍCULO}

\begin{tabular}{|c|c|}
\hline $\begin{array}{l}\text { Reference / } \\
\text { Referencia }\end{array}$ & $\begin{array}{l}\text { Biencinto-López, Chantal, González-Barbera, Coral, García-García, Mercedes, Sánchez-Delgado, Purifica- } \\
\text { ción, Madrid-Vivar, Dolores (2009). Diseño y propiedades psicométricas del AVACO-EVADIE. Cuestio- } \\
\text { nario para la evaluación de la atención a la diversidad como dimensión educativa en las instituciones esco- } \\
\text { lares . } \underline{R E L I E V E}, \text { v. 15, n. 1. http://www.uv.es/RELIEVE/v15n1/RELIEVEv15n1_4.htm. Consultado en } \\
\text { (poner fecha). }\end{array}$ \\
\hline Title / Título & $\begin{array}{l}\text { Diseño y propiedades psicométricas del AVACO-EVADIE. Cuestionario para la evaluación de la aten- } \\
\text { ción a la diversidad como dimensión educativa en las instituciones escolares . [Design and psychometric } \\
\text { properties of AVACO-EVADIE. Questionnaire for the evaluation of the diversity attention as an educa- } \\
\text { tional dimension in the school institutions] }\end{array}$ \\
\hline $\begin{array}{l}\text { Authors / } \\
\text { Autores }\end{array}$ & $\begin{array}{l}\text { Biencinto-López, Chantal, González-Barbera, Coral, García-García, Mercedes, Sánchez-Delgado, Purifica- } \\
\text { ción, Madrid-Vivar, Dolores }\end{array}$ \\
\hline $\begin{array}{l}\text { Review } \\
\text { / Revista }\end{array}$ & Revista ELectrónica de Investigación y EValuación Educativa (RELIEVE), v. 15, n. 1 \\
\hline ISSN & $1134-4032$ \\
\hline $\begin{array}{l}\text { Publication } \\
\text { date / } \\
\text { Fecha de } \\
\text { publicación }\end{array}$ & $\begin{array}{l}2008 \text { (Reception Date: } 2009 \text { September 28; Approval Date: } 2009 \text { April 5; Publication Date: } 2009 \\
\text { April 6). }\end{array}$ \\
\hline $\begin{array}{l}\text { Abstract / } \\
\text { Resumen }\end{array}$ & $\begin{array}{l}\text { This article shows the process taken to design and identify the psychometric properties of the evaluation } \\
\text { instrument construct Diversity Attention as a context variable. For that, the starting point is a brief revision } \\
\text { of different instruments used to collect information on diversity, not only cultural but also social, linguistic } \\
\text { or on capacities. After that, and assuming a classification of the different theoretical approaches, a first } \\
\text { instrument is made, committing ourselves to an inclusive approach. After that, its validation is made by } \\
\text { experts and its pilot study is carried on. Reliability analysis of the instrument helps us to conclude that the } \\
\text { questionnaire is reliable on collecting information regarding how schools face diversity attention. } \\
\text { El presente artículo muestra el proceso seguido para diseñar e identificar las propiedades psicométricas del } \\
\text { instrumento de evaluación del constructo Atención a la Diversidad como variable de contexto. Para ello, se } \\
\text { ha comenzado con una pequeña revisión de los instrumentos utilizados para recoger información sobre la } \\
\text { diversidad tanto cultural como social, lingüística o en capacidades. A continuación y, partiendo de una } \\
\text { clasificación de los distintos enfoques teóricos, se ha construido un primer instrumento, apostando por un } \\
\text { enfoque inclusivo. Posteriormente se procede a una validación por expertos. Tras la validación se toma la } \\
\text { decisión de subdividir el instrumento original en cuatro instrumentos, uno por audiencia encuestada y por } \\
\text { último al pilotaje del mismo. El análisis de la fiabilidad del instrumento nos lleva a la conclusión de que se } \\
\text { trata de un cuestionario fiable para recoger información acerca de como afrontan los centros la Atención a } \\
\text { la Diversidad. }\end{array}$ \\
\hline \begin{tabular}{l|} 
Keywords / \\
Descriptores
\end{tabular} & $\begin{array}{l}\text { Diversity attention, context variables, inclusive approach, evaluation of educational systems. } \\
\text { Atención a la diversidad, variables de contexto, perspectiva inclusiva, evaluación de sistemas educativos. }\end{array}$ \\
\hline $\begin{array}{l}\text { Institution / } \\
\text { Institución }\end{array}$ & Universidad Complutense de Madrid; Universidad de Valencia; Universidad de Málaga. (España). \\
\hline $\begin{array}{l}\text { Publication } \\
\text { site / } \\
\text { Dirección }\end{array}$ & http://www.uv.es/RELIEVE \\
\hline $\begin{array}{l}\text { Language / } \\
\text { Idioma }\end{array}$ & Español (Title, abstract and keywords in English ) \\
\hline
\end{tabular}




\section{(RELIEVE)}

\section{Revista ELectrónica de Investigación y $\mathbf{E V}$ aluación Educativa E-Journal of Educational Research, Assessment and Evaluation}

[ ISSN: 1134-4032 ]

(C) Copyright, RELIEVE. Reproduction and distribution of this articles it is authorized if the content is no modified and their origin is indicated (RELIEVE Journal, volume, number and electronic address of the document).

(C) Copyright, RELIEVE. Se autoriza la reproducción y distribución de este artículo siempre que no se modifique el contenido y se indique su origen (RELIEVE, volumen, número y dirección electrónica del documento). 